\title{
Why do international assignees stay? An organizational embeddedness perspective
}

\author{
B. Sebastian Reiche \\ Maria L. Kraimer \\ Anne-Wil Harzing
}

Version October 2010

To be published in Journal of International Business Studies, 2011

Copyright @ 2008-2010 Sebastian Reiche, Maria Kraimer \& Anne-Wil Harzing. All rights reserved.

Prof. Anne-Wil Harzing University of Melbourne

Department of Management \& Marketing

Faculty of Economics \& Commerce

Parkville Campus

Melbourne, VIC 3010

Australia
Email: anne-wil@harzing.com

Web: www.harzing.com 


\title{
WHY DO INTERNATIONAL ASSIGNEES STAY? AN ORGANIZATIONAL EMBEDDEDNESS PERSPECTIVE
}

\begin{abstract}
We apply an organizational embeddedness perspective to examine international assignees’ retention with the organization. Specifically, we hypothesize that assignees' social ties within and their perceived fit with the host unit positively relate to two sacrifices with leaving the organization: their firmspecific learning during the assignment and their perceived career prospects in the organization. Perceived career prospects is expected to predict subsequent retention, moderated by firm-specific learning. These hypotheses are tested using a sample of 143 inpatriates in ten German multinationals with retention measured two and four years later. We show that inpatriates' trusting ties with HQ staff and their fit with the HQ positively relates to their firm-specific learning and their perceived career prospects, and that the latter predicts their retention two and four years later. Perceived career prospects mediates the direct relationship between inpatriates’ fit with the HQ and inpatriate retention, and the indirect relationship between inpatriates’ trusting ties with HQ staff and their retention. Furthermore, inpatriates' firm-specific learning mitigates the effect of perceived career prospects on retention decisions two years later. We contribute to the organizational embeddedness, careers, and international business literatures by explaining when and how facets of organizational embeddedness relate to assignee retention.
\end{abstract}

Keywords: international assignments, organizational embeddedness, retention, career prospects, learning organizational knowledge 


\section{INTRODUCTION}

The retention of international assignees is particularly important in multinational corporations (MNCs). A key motive for international staff transfers is not only to accomplish a specific task during the assignment, but also to contribute to the long-term development of both individual talent and the larger organization (Edström \& Galbraith, 1977; Gregersen, Morrison, \& Black, 1998). For example, we know from the academic and practitioner literatures that international assignees serve as knowledge agents between MNC units both during their assignments and upon repatriation to their home units (Furuya, Stevens, Bird, Oddou, \& Mendenhall, 2009; Reiche, Harzing, \& Kraimer, 2009). However, the high risk of repatriate turnover as shown by several studies (Stahl, Miller, \& Tung, 2002; Stroh, Gregersen, \& Black, 1998) suggests that MNCs may not be able to capitalize on such benefits once the assignee returns to his or her home country (i.e., repatriates). Despite the high risk of turnover, the factors that determine whether employees with international assignment experience choose to remain with their organizations are largely unclear.

Addressing this gap in our knowledge, we adopt an organizational embeddedness perspective to investigate factors that facilitate retention of international assignees in MNCs. Drawing on job embeddedness theory (Lee, Mitchell, Sablynski, Burton, \& Holtom, 2004; Mitchell, Holtom, Lee, Sablynski, \& Erez, 2001), Ng and Feldman (2007) defined organizational embeddedness as the totality of forces that keep people in their current organizations. It is broader than Mitchell and colleagues’ (2001) job embeddedness construct in that it allows for inter-job mobility within an organization, yet at the same time, is narrower in that it is not concerned with off-the-job, or community, embeddedness (Feldman \& Ng, 2007; Ng \& Feldman, 2007). These scholars proposed that individuals are embedded in their organizations to the extent that they have formal or informal links with organizational members, perceive that they fit the organization, and perceive sacrifices with leaving the organization. We apply this organizational embeddedness framework to develop and test a model of international assignee retention by the MNC (see Figure 1). 
Insert Figure 1 about here

Specifically, we propose that international assignees’ links to host-unit members and perceived fit with the host unit are positively related to benefits that may be sacrificed upon leaving the organization: firm-specific learning acquired through the international assignment and perceived career prospects within the MNC. Perceived career prospects is in turn expected to mediate the relationship between links/fit and retention two and four years later. However, we expect the relationship between perceived career prospects and retention to be moderated by the more immediate sacrifice associated with firm-specific learning. When assignees perceive that they have learned a great deal from their international assignments (high firm-specific learning), perceived career prospects is not expected to mediate the relationships between links and fit, and the retention decision. We test our hypotheses using a particular group of international assignees - inpatriates. Inpatriates are employees from foreign subsidiaries that are temporarily transferred to a MNC’s corporate headquarters (HQ) (Harvey, Novicevic, \& Speier, 1999). We chose to investigate inpatriates because MNCs are increasingly using inpatriate assignments to develop talent in its foreign subsidiaries as an alternative to the more expensive staffing strategy of expatriating employees from HQs to foreign subsidiaries (Tharenou \& Harvey, 2006). Retention of inpatriates is thus crucial to the success of this strategy for staffing foreign subsidiaries.

Our study contributes to research on retention by testing factors that are thought to embed international assignees in the organization. Theoretically, we build on previous retention/turnover studies that propose a hierarchy of attachment drivers (see Holtom, Mitchell, Lee, \& Eberly, 2008) and contend that the three facets of organizational embeddedness do not influence retention in the same, direct manner. Rather, we integrate social resources, social identity, and social exchange theory arguments to conceptualize how perceived sacrifices may mediate or moderate the relationships between links/fit and retention. We also contribute both empirically and theoretically to the careers literature by providing a longitudinal test of the effect of perceived career prospects on actual retention two and four years later, 
extending existing research that has largely focused on measuring turnover intentions (e.g., Bigliardi, Petroni, \& Dormio, 2005; Chay \& Aryee, 1999; Stahl, Chua, Caligiuri, Cerdin, \& Taniguchi, 2009). In addition, we conceptualize the role of firm-specific learning as a variable that may explain why research on international assignees thus far has failed to establish a link between perceptions of internal career prospects and turnover intentions (cf., Stahl et al., 2009; Van der Heijden, van Engen, \& Paauwe, 2009).

We also contribute to the international business literature. Whereas international assignments have long been regarded as a key mechanism for MNCs to develop international competencies among its staff (Furuya et al., 2009; Gregersen et al., 1998) and diffuse firm-specific knowledge across MNC units (Hocking, Brown, \& Harzing, 2007; Reiche et al., 2009), few studies have examined how such knowledge and expertise is acquired by the individual assignee. In this vein, our study investigates two specific antecedents -- links with host-unit staff and fit with the host unit -- that may relate to assignees’ acquisition of firm-specific knowledge. We also consider whether this knowledge helps embed them in the MNC leading to increased retention. One reason for the prevailing uncertainty about the scale of assignee failure rates (Harzing \& Christensen, 2004) is that very few, if any, studies on international assignees measure actual turnover through a longitudinal design. From an empirical perspective, our study is unique in collecting such data over a period of four years. Finally, we focus on inpatriates, a group of international employees that has received relatively little attention in the literature compared to expatriates (Harvey et al., 1999; Tharenou \& Harvey, 2006). Yet, as we discuss in the next section, there are fundamental differences between inpatriates and expatriates that suggest it is important to build and/or test theoretical models that recognize these differences.

\section{THE ROLE OF INPATRIATE ASSIGNMENTS IN MNCS}

The temporary inpatriation of subsidiary staff into the HQ of MNCs is an international assignment strategy that is receiving increasing attention both in academic research (Harvey, Novicevic, Buckley, \& Fung, 2005; Reiche, 2006) and corporate practice (Oddou, Gregersen, Black, \& Derr, 2001; Tharenou \& Harvey, 2006). Like expatriation (i.e., the transfer of parent-country nationals from the HQ to foreign 
subsidiaries), inpatriation serves as a developmental relocation that provides assignees with corporate socialization and firm-specific training, thereby preparing them for future management roles in the organization. Given the intimate understanding of both the local subsidiary and the HQ context that inpatriates develop, they are able to span existing boundaries within the MNC, ultimately enabling the HQ to establish greater social control towards its foreign units (Harvey et al., 1999). Thus, MNCs may derive ongoing benefits from former inpatriates as long as the latter continue to act as boundary spanners upon their repatriation. For example, inpatriates can convey their acquired knowledge about the HQ culture and environment to subsidiary staff, thus further enriching the cross-unit links. For these reasons, the retention of inpatriates is particularly important for MNCs.

Inpatriates, however, face unique challenges that expatriates often do not experience. First, whereas expatriates carry with them the status and influence that is associated with their role as HQ representatives, inpatriates, coming from a foreign subsidiary, are unlikely to encounter the same level of credibility and respect (Harvey et al., 2005). Second, inpatriates may have increased adjustment challenges compared to expatriates since inpatriates not only have to adapt to the host national culture but also need to be socialized into the MNC’s HQ corporate culture. In contrast, expatriates often impose elements of the HQ corporate culture upon the subsidiary to which they are sent (Harvey et al., 1999). Shaffer, Harrison and Gilley (1999) demonstrated that inpatriates experience substantially different adjustment processes in the host country compared to expatriates. Third, inpatriates are expected to collaborate with the host unit's (i.e., HQ’s) management team whereas expatriates generally continue to coordinate with their own home-country management team. Together, these unique challenges suggest that it is especially important for inpatriates to develop links to colleagues within, and shared values with, the HQ (i.e., to be embedded in the organization) in order for inpatriates to serve the boundary-spanning role discussed earlier (Kostova \& Roth, 2003; Reiche et al., 2009). Initial conceptual (Farh, Bartol, Shapiro, \& Shin, 2010; Toh \& DeNisi, 2007) and empirical (Liu \& Shaffer, 2005; Wang \& Kanungo, 2004) research indeed suggests that international assignees need to develop social relationships at the host unit to succeed on their assignments. For example, Wang and Kanungo (2004) found that assignees’ social 
ties influenced their psychological well-being in the host unit. An organizational embeddedness perspective of retention is therefore particularly relevant for inpatriates. We develop our theoretical model in the inpatriate context to complement the prior expatriate-focused literature.

Consistent with Ng and Feldman’s (2007) conceptualization of organizational embeddedness, we propose that inpatriates’ organizational embeddedness may involve three elements: links with host-unit colleagues; fit to the host unit; and sacrifices associated with leaving the MNC that stem from their international assignments. We define inpatriates’ links to host-unit colleagues in terms of the number of ties they have to higher-level managers (higher than themselves) at HQ and the average trust in their social network at HQ, where social network is defined as the individuals they interact with on a regular basis at work. Our definition of links addresses the recent call for moving beyond the original job embeddedness construct to include social network theory and methodology to more explicitly measure links to organizational members (Holtom et al., 2008; Hom, Boudwin, \& Allen, 2009). We define inpatriates’ fit as the extent to which they identify with the HQ's values and goals consistent with our focus on organizational embeddedness (e.g., Ng \& Feldman, 2007).

Finally, we consider two distinct organizational benefits that constitute sacrifices upon leaving the organization. First, the firm-specific knowledge an inpatriate develops during the HQ assignment may be sacrificed upon leaving the organization because such knowledge cannot be deployed to the same extent at other organizations (Coff, 1997). A second benefit that may be sacrificed by leaving the organization is any future career prospects an inpatriate perceives in the organization as a result of his or her international assignment. We examine career prospects as a perceptual construct to reflect the fact that recent conceptualizations of career success emphasize the subjective, individualized nature of the meaning of success (Heslin, 2005). Mitchell et al. (2001) recognized future career prospects as a potential sacrifice of leaving the organization in developing their measure for on-the-job sacrifices. Overall, our definitions of inpatriates' links, fit, and sacrifices recognize the unique ways that inpatriates may be embedded in their organizations. 


\section{THEORY AND HYPOTHESES}

Figure 1 illustrates our theoretical model. At a general level, we contend that inpatriates’ willingness to remain in the MNC over time may depend on the level of organizational embeddedness they develop during their HQ assignments. Whereas the organizational embeddedness perspective provides an overarching theoretical lens in our study, our focus is on developing the relationships among the dimensions of organizational embeddedness vis-à-vis retention. In doing so, we more fully develop the theoretical logic for why organizational embeddedness is related to retention by integrating three relevant theories. Specifically, we use social resources theory to develop the role of inpatriates' links with HQ staff (Hypotheses 1, 2, and 6a), social identity theory to theorize about the role of inpatriates' fit and shared values with the HQ (Hypotheses 3, 4, and 6b), and social exchange theory to conceptualize retention as the outcome of inpatriates’ cost-benefit analysis of remaining in the MNC (Hypotheses 5 and 7).

\section{Inpatriates’ Links with HQ Staff and Benefits Sacrificed upon Leaving}

According to social resources theory (Lin, Ensel, \& Vaughn, 1981; Mardsen \& Hurlbert, 1988), individuals in one’s informal social network (i.e., their social ties) are resources to the extent that the social ties provide information or support that help the individual achieve his or her goals. We assume that a broad goal for inpatriates is to be successful in their inpatriate assignments and we propose that by building social ties with higher-level managers, inpatriates will be able to access information, gain support, and receive opportunities necessary to achieve this goal (Cross \& Cummings, 2004; Lin et al., 1981). For example, research has found that one’s ties to higher-level managers is positively related to access to strategic information and career sponsorship (Seibert, Kraimer, \& Liden, 2001), as well as interunit feedback and advice in MNCs (Barner-Rasmussen, 2003). Theoretically, we would also expect that individuals are more likely to share information and advice with other individuals with whom they share a trusting relationship (e.g., Granovetter, 1973; Tsai \& Ghoshal, 1998). Indeed, there is evidence that strong and trustworthy ties facilitate the transfer of tacit knowledge, both in the domestic (Hansen, 1999; Reagans \& McEvily, 2003) and international context (Mäkelä \& Brewster, 2009; Reiche et al., 2009). We 
therefore expect both ties to higher level-managers and average trust in the network to be positively related to both sacrifice variables: firm-specific learning and perceived career prospects in the MNC.

With regard to firm-specific learning, links with higher-level managers at HQ can provide inpatriates with valuable resources and information specific to the HQ. For example, through their social ties with higher-level managers, inpatriates may receive advice on how to produce a project report in line with HQ standards. Such advice allows them to more readily accomplish their assignment objectives. In a related vein, Borgatti and Cross (2003) demonstrated that an individual's social ties with other organizational members enable the individual to learn more about what these colleagues know, which in turn facilitates the individual's search for relevant information. Similarly, scholars have argued that international assignees' social ties to host-unit staff may influence the volume and diversity of knowledge assignees acquire during their relocation (Reiche et al., 2009). Thus, developing a large network of hostunit colleagues at higher levels in the organization is important to inpatriates' learning because higherlevel ties are more likely to be in positions to provide valuable information, and the more ties inpatriates have the more likely they are to seek information. Similarly, research has demonstrated that individuals are more likely to share tacit knowledge with others when there is a trusting relationship (Mäkelä \& Brewster, 2009; Reagans \& McEvily, 2003; Seibert et al., 2001). Because a large part of inpatriates’ learning constitutes tacit knowledge that is specific to the organization they work in, for example learning the HQ corporate culture (Harvey et al., 1999), developing trusting relationships with HQ staff should be important for inpatriates’ learning of firm-specific knowledge.

Hypothesis 1. Inpatriates' links with HQ staff (defined as ties to higher-level managers and average trust in network) will positively relate to their firm-specific learning during the assignment.

We also expect that inpatriates’ links with HQ staff are positively related to inpatriates’ perceived career prospects within the MNC. Given the informational resources that are rooted in inpatriates' social ties to higher-level managers at HQ (Lin et al., 1981), inpatriates that are linked to more higher-level 
managers are likely to be more successful in their assignments. In this vein, there is evidence that access to host-unit information and resources positively relates to expatriate performance (Liu \& Shaffer, 2005). Likewise, individuals are more likely to give career advice and assistance to their colleagues when they have a trusting relationship (Granovetter, 1973). Such sharing of information and advice should allow inpatriates to be more successful in their jobs. Individuals who are successful in their assignments should perceive greater career prospects within the MNC because many organizations reward successful job performance with promotional opportunities (Judge, Cable, Boudreau, \& Bretz, 1995; Lyness \& Thompson, 2000). This is particularly true for foreign subsidiary employees for whom a HQ assignment is considered vital to gain access to higher management levels within the MNC (Reiche, 2006). Success in the inpatriate assignment may also provide inpatriates with positive exposure and visibility at the HQ, allowing them greater latitude to pursue positions that match their own career goals. This is consistent with research that has shown that individuals with more social ties to higher levels in their organizations and with more strong ties in their professional advice network received more career sponsorship, access to information, and greater extrinsic and intrinsic career success (Bian, 1997; Seibert et al., 2001).

Hypothesis 2. Inpatriates' links with HQ staff (defined as ties to higher-level managers and average trust in network) will positively relate to their perceived career prospects in the MNC.

\section{Inpatriates’ Fit with the HQ and Benefits Sacrificed upon Leaving}

We expect that inpatriates' perceived fit with the HQ’s values and goals positively relates to both their firm-specific learning and perceived career prospects due to the individual benefits derived from sharing a common social identity with organizational members (Ashforth, Harrison, \& Corley, 2008). According to social identity theory, individuals classify themselves into social categories based on groups to which they belong, including organizations, and individuals who strongly identify with their organizations internalize the organization's values and norms (Ashforth \& Mael, 1989). Concerning firmspecific learning, a shared identification with the organization's values and goals prevents misunderstandings when communicating with organizational members about firm-specific practices and 
routines, and enables members to recognize the potential value of their knowledge exchange (Tsai \& Ghoshal, 1998). This is particularly important in a cross-national context, where knowledge may be instilled with culture-specific meanings (e.g., Bhagat, Kedia, Harveston, \& Triandis, 2002). Indeed, research has found that the existence of a shared social identity between an assignee and members of the organizational unit the assignee has entered facilitates the transfer of knowledge (Kane, Argote, \& Levine, 2005) and motivates members of the unit to engage in socializing behaviors such as the provision of role information and social support towards the assignee (Toh \& DeNisi, 2007). There is also evidence that shared social identities facilitate knowledge sharing at the MNC unit level (Björkman, Barner-Rasmussen, \& Li, 2004; Kostova \& Roth, 2002). In sum, we expect that inpatriates’ shared values and goals with the HQ enable inpatriates to attribute more value to knowledge exchange with locals, and elicit more firmspecific information from host-unit colleagues, thus increasing inpatriates’ firm-specific learning.

Hypothesis 3. Inpatriates' fit with the HQ will positively relate to their firm-specific learning during the assignment.

With regard to perceived career prospects, if an individual's values match those of the organization, $\mathrm{s} /$ he is better able to understand what is required to advance in the organization. This is because individuals that share organizational values are more likely to identify with the organization (Ashforth \& Mael, 1989), and thus, have more clear and consistent expectations about their role and future career opportunities (Podolny \& Baron, 1997). For example, the literature on socialization emphasizes that communicating the values and ways of working collectively to new members helps shape their expectations about job-related behaviors (Chatman, 1991; Louis, 1980). Existing research supports the notion that value congruence between the individual and the organization relates to job opportunities (Bretz \& Judge, 1994). Taken together, this suggests that the more inpatriates perceive that they fit with the HQ’s values and goals, the more likely they will perceive that their inpatriate assignment is preparing them for future career opportunities in the organization. 
Hypothesis 4. Inpatriates' fit with the HQ will positively relate to their perceived career prospects in the MNC.

\section{Inpatriates’ Benefits Sacrificed upon Leaving and Retention}

Of the two organizational benefits that may be sacrificed by leaving the organization, we contend that only perceived career prospects within the MNC will be directly related to retention. This is because perceived career prospects may represent a future benefit, or a future cost, of remaining in the organization, depending on whether the inpatriate perceives many or no career prospects for herself. Having many future opportunities is a benefit that the inpatriate would have to sacrifice if she left the organization. However, having very few future career opportunities would represent a cost of remaining with the MNC (e.g., the inpatriate's career and pay may stagnate by staying in the organization). On the other hand, we do not expect firm-specific learning to directly covary with the likelihood of retention because, although high levels of firm-specific learning represent a past investment in the organization for which inpatriates may receive organizational benefits, the lack of investment in firm-specific learning does not necessarily imply a cost to remaining in the organization. That is, inpatriates who did not invest a great deal of time and energy into learning firm-specific knowledge will not have invested time and energy in any other organization either. Regardless of the low firm-specific learning, the inpatriate may perceive that other job benefits exist, which may embed him/her in the MNC. For these reasons, we do not expect firm-specific learning to be directly related to retention, but rather we propose that firm-specific learning moderates the impact of perceived career prospects on retention in Hypothesis 7.

Social exchange theory (Blau, 1964; Homans, 1961) provides a theoretical explanation for our contention that future career prospects are important to retention decisions. The core tenet of social exchange theory is that every human relationship is formed based on a subjective cost-benefit analysis and a comparison with alternative relationships. If an individual perceives the costs of a relationship to outweigh the perceived benefits, then the individual is likely to discontinue the relationship. One such cost would be a lack of career prospects within the organization. Without career prospects, the individual may 
not enjoy the associated intrinsic and extrinsic rewards that come with career progress. On the other hand, when valued career prospects are perceived to be present in the organization, the employee has greater motivation to remain in the organization. The possibility that their careers can unfold within the current organization will make employees feel embedded with the organization because leaving would represent a sacrifice of valued rewards associated with career prospects (Mitchell et al., 2001). In support of this argument, there is evidence that promotional chances are negatively related to turnover (Maertz \& Campion, 2004). However, with regard to international assignees specifically, surprisingly two recent studies found that perceived internal career prospects were not significantly related to expatriates’ turnover intentions (Stahl et al., 2009; Van der Heijden et al., 2009). Nonetheless, given the number of researchers who have argued that it is important for international assignees to perceive a link between their assignment and their long-term career prospects in order for MNCs to retain assignees (Feldman \& Thomas, 1992; Lazarova \& Caligiuri, 2001; Stroh et al., 1998), we hypothesize that there will be a positive relationship between perceived career prospects and retention.

Hypothesis 5. Inpatriates' perceived career prospects in the MNC will positively relate to their retention in the MNC.

\section{Perceived Career Prospects as a Mediator}

Hypotheses 2, 4, and 5 combined suggest a model in which perceived career prospects mediates the effects of inpatriates' links and fit on their retention. Theoretically, we expect perceived career prospects to mediate both relationships for two reasons. First, with regard to links and retention, social resources theory (Lin et al., 1981) suggests that it is not the network ties in and of themselves that impact individuals' behaviors, but rather the resources embedded in those ties that lead to various behavioral outcomes. Social networks provide access to resources, such as task-related information (BarnerRasmussen, 2003; Cross \& Cummings, 2004) and information about job opportunities (Seibert et al., 2001), and it is this access to information and resources that informs individuals' behavioral decisions. Second, with regard to fit and retention, social identity theory suggests that shared values provide 
individuals with a common understanding of how things "work” in the organization (Ashforth \& Mael, 1989; Erdogan, Kraimer, \& Liden, 2004). A shared understanding helps one form positive attitudes and beliefs about the organization, including one's career prospects, which in turn impact more distal outcomes such as turnover (O’Reilly, Chatman, \& Caldwell, 1991). In short, one’s links to organizational members and fit to the organization are a means to obtaining career prospects, which would be sacrificed by leaving the organization. Thus, we expect that inpatriates with greater links and fit at the HQ will perceive greater career prospects within the organization, which in turn impacts retention.

Hypothesis 6a. Perceived career prospects will mediate the relationship between inpatriates' links with HQ staff and retention in the MNC.

Hypothesis 6b. Perceived career prospects will mediate the relationship between inpatriates' fit with the HQ and retention in the MNC.

\section{Firm-Specific Learning as a Moderator}

Finally, we contend that inpatriates’ firm-specific learning during the assignment moderates the relationship between perceived career prospects and retention. This is because firm-specific learning during the inpatriate assignment represents a significant and recent investment in the organization by the employee. The immediate costs of leaving the organization become greater as inpatriates acquire more firm-specific knowledge (Coff, 1997). Thus, high-levels of firm-specific learning during the inpatriate assignment may mitigate the importance of future career prospects to retention decisions. Specifically, when inpatriates’ firm-specific learning is high, social exchange theory suggests that a potential future benefit, such as career prospects, may be less important to retention decisions. This is because the future benefit may not outweigh the costs associated with terminating the employee-organization relationship (Homans, 1961). When individuals have invested personal resources (i.e., money, time, or effort) into learning about a specific job and organizational unit, the employee is motivated to remain in the organization in order to, theoretically, benefit from immediate rewards the organization should reciprocate, such as salary raises, job security or more interesting and stimulating work (Maurer, Weiss, \& 
Barbeite, 2003). Applied to inpatriate assignments, not only did inpatriates invest the time and energy in moving to a foreign country and developing relationships at the HQ (Shen \& Hall, 2009), but they also acquired firm-specific knowledge about the HQ that would not be relevant at other organizations. As a result, social exchange theory suggests that such inpatriates will be motivated to remain with the organization due to the expectation that the organization will reciprocate by rewarding the inpatriate for their investment in learning. In contrast, when inpatriates do not perceive they have acquired a great deal of firm-specific knowledge during the assignment (i.e., low firm-specific learning), the costs associated with their assignments are lower due to their lower investments in firm-specific learning. In fact, their international experience may serve to provide them with greater external labor mobility to the extent that other MNCs value international experience (Stahl et al., 2002). In the case of low firm-specific learning, future career prospects are an important determinant of retention decisions as argued above.

Hypothesis 7. Inpatriates' firm-specific learning during the assignment will moderate the positive relationship between inpatriates' perceived career prospects and their retention in the MNC such that the relationship will be stronger when firm-specific learning is low, compared to when learning is high.

\section{METHODS}

\section{Sample and Procedures}

To test the proposed relationships, an on-line survey was administered to a sample of 643 inpatriates at 10 German MNCs’ HQs. These MNCs represent six industries: automotive, aviation, banking, chemical, consumer goods, and pharmaceutical. Their worldwide staff ranges from 15,900 to 344,900 and HQ staff ranges from 2,070 to 51,000 employees. The national culture of the assignment destination was held constant to reduce potential variation due to cultural differences of the assignment context (Mendenhall \& Oddou, 1985). We selected German companies for this study because Oddou et al. (2001) found that European MNCs in particular expect to increase their share of inpatriates in the future and because data collection could be facilitated since one of the authors had contacts at several German 
companies. The HR manager at each of the 10 MNCs agreed to cooperate with our study by inviting all of their inpatriates to participate in our on-line survey. Respondents had the choice to complete the survey either in English or in German (88\% completed the survey in English). Confidentiality of survey responses was ensured to all participants. A reminder email was sent two weeks after the initial email. A total of 286 inpatriates completed the survey (a 44.5\% response rate). The respondents came from a total of 45 different countries-of-origin, 76\% were male, and 79\% were married or had a partner. Their average age was 37 years. Their average organizational tenure was 9.4 years and they had spent an average of 24.5 months on their current assignments.

Of the 286 survey respondents, 143 could be identified by their email address they voluntarily provided at the end of the survey. We obtained our retention data on these 143 respondents from company records at two different points in time: two and four years after the initial survey. We chose a time lag of 2 years between survey administration and the collection of initial retention data because, according to the companies' HR managers, the average inpatriate assignment lasts between 3-4 years in these companies. When collecting the initial retention data, we were able to include both those individuals that were still on assignment and those that had already completed their inpatriate assignment since our respondents had on average spent 2 years on their assignments at the time of initial data collection. Of the 143 respondents, 26 were still on their inpatriate assignments after two years whereas all respondents had completed their inpatriate assignments at the 4-year mark. All hypotheses are tested with these 143 respondents. These respondents came from all 10 German MNCs, with the responses per company ranging from 5 to 33 . The 143 respondents came from a total of 32 different countries-of-origin, they were mostly male (81.8\%), and $79.7 \%$ of respondents were married or had a partner. Their average age at the time of initial data collection was 37.36 years and their average organizational tenure 9.24 years. The demographic characteristics of the 143 respondents are very similar to the full survey sample, indicating that this subsample is representative of the larger sample. The 12 respondents (8.4\%) that had left after two years were mostly male (75\%) and $66.7 \%$ were married or had a partner. Their average age at the time of initial data collection was 41 years. 
Of those 23 respondents (16.1\%) that had left after four years, $73.9 \%$ were male and $60.9 \%$ were married or had a partner. Their average age at the time of initial data collection was 38.3 years.

To ensure language equivalence between the English and German versions of the questionnaire, we adopted the following approach. First, we constructed the questionnaire in English, using simple sentence structures as well as clear and familiar wording as much as possible to facilitate subsequent translation. We then used the back-translation technique (Brislin, 1970) to produce the German-language version. We presented the original English version to a bilingual colleague and asked for a translation into German. Subsequently, a second bilingual colleague translated this German version back into English. Given the first author's fluency in both languages, a sound assessment about existing variations could be made, which were then discussed with both translators. After a few minor modifications to both language versions, the translation was considered satisfactory. Thirty respondents completed the survey in German with 23 being among the 143 responses used for testing our hypotheses. The number of German language respondents is thus too small to allow us to conduct more sophisticated tests for measurement equivalence across the two language groups. However, we do control for survey language when testing our hypotheses. Out of the 23 individuals who responded in German, 3 (13\%) had left their companies after two years and 4 (17.4\%) had left after four years. In comparison to the 120 individuals answering in English, 9 (7.5\%) had left after two years and 19 (15.8\%) after four years. Following Van de Vijver and Leung (1997), we also tested for differences in the reliability coefficients of our variables across the English and German responses. As reported below, no significant differences were found.

\section{Measures}

To avoid consistency bias in participants' responses, we combined the use of ego-network and perception-based question formats. All variables were rated by inpatriates and measured on the survey except for inpatriate retention. The scales of the perception-based measures (fit with the HQ, perceived career prospects, and inpatriate learning of firm-specific knowledge) are reproduced in the Appendix. 
Links. We followed an ego-network approach to data collection (Burt, 1992) to measure inpatriates’ links with HQ staff. Respondents were asked to consider up to ten people with whom they interacted on an everyday basis, and answer a range of questions with regard to every person they identified. Following our theoretical arguments, we operationalized links in terms of ties to higher-level managers and average trust in network. As a result, we asked respondents whether their respective contact person occupied a lower, same, or higher hierarchical position compared to them. We then calculated a single aggregate number of ties to higher-level managers, ranging from 0 (if none of the contact persons occupied a higher level than the respondent) to 10 (if the respondent identified the maximum of 10 contact persons, all of which occupied a higher level). The use of such a single-item measure is consistent with existing social network research to measure structural characteristics of an individual's network, including the number of higher-level ties (e.g., Cross \& Cummings, 2004; Wang \& Kanungo, 2004). Based on previous research (e.g., Seibert et al., 2001; Tsai \& Ghoshal, 1998), average trust in network was measured by asking respondents to indicate for each contact person listed in their ego network: "To which extent can you rely on this person without any fear that s/he will take advantage of you?," "To which extent do you think this person feels that s/he can rely on you without any fear that s/he will be taken advantage of by you?" ( 1 = not at all to 7 = to a great extent $)$, and "How close is your relationship with this colleague?” $(1=$ not at all close to 7 = extremely close $)$. We aggregated all three items for each contact reported by a respondent and then calculated an average score of trust for each respondent's entire ego-network ( $\alpha=.78$ for English survey responses, $\alpha=.73$ for German responses). The difference in reliability coefficients across both language groups is insignificant $(F=.82, p>.05)$.

Fit with the HQ. To operationalize inpatriates' fit with the HQ, we constructed a three-item scale (see Appendix) based on Tsai and Ghoshal (1998) and Reade (2001). The three items were averaged to create a scale score for fit with HQ ( $\alpha=.80$ for English survey responses, $\alpha=.83$ for German responses). The difference in reliability coefficients across both language groups is insignificant $(F=1.18, p>.05)$.

Perceived career prospects. As no valid, established measure of perceived career prospects was available in the context of inpatriate assignments, we had to develop a new measure (see Appendix for the 
five items). We developed items based on existing research indicating that the construct of perceived career prospects entails two principal content dimensions, (1) the extent to which individuals see a clear link between their current international assignment and their overall career plan (e.g., Feldman \& Thomas, 1992), and (2) assignees’ perception of fit between their individual and the organizational career plans (e.g., Granrose \& Portwood, 1987). To evaluate the content validity of our measure, we subjected our items to an assessment by four scholars with expertise in the careers and international assignment literatures. To check for face validity of our final five-item measure, we interviewed a random sample of 8 inpatriates at a German MNC as part of a survey pilot test to confirm that these items are relevant for them. The five items that appear in the Appendix were confirmed as being relevant by all 8 inpatriates, and were, thus, included on our study survey. The five items were averaged to create a scale score $(\alpha=$ .93; same alpha coefficient for both English and German responses). To ensure internal consistency, we measured perceived career prospects again as part of a separate survey that was sent to the same inpatriate sample two years after the initial data collection. This resulted in a similar level of reliability $(\alpha=.93)$.

Inpatriate learning of firm-specific knowledge. Similar to the variable of perceived career prospects, we had to establish a measure of learning of firm-specific knowledge that is specific to the inpatriate context. Given the role of inpatriate assignments for the socialization and professional development of foreign nationals at the HQ (Harvey et al., 1999; Reiche, 2006), we focused on these types of firm-specific knowledge acquired by inpatriates in developing our items. We developed a four-item scale of inpatriate learning (see Appendix), following the same procedure explained earlier to assess content and face validity of our measure. We averaged the four items to create a scale score $(\alpha=.82$ for English survey responses, $\alpha=.89$ for German responses). The difference in reliability coefficients across both language groups is insignificant $(F=1.64, p>.05)$.

Retention. Two and four years after the survey administration, the HR managers provided us with retention data from company records (coded $1=$ still with the same $M N C, 0=$ left the $M N C$ ). We confirmed with the respective HR manager that all respondents that had left the company had done so voluntarily. The retention rate was $91.6 \%$ two years and $83.9 \%$ four years after initial data collection. 
Control variables. We measured several control variables to improve our model estimation. Due to the potential effect of various demographic characteristics (gender, age, organizational tenure) and network characteristics (network size) on career prospects (e.g., Judge et al., 1995; Seibert et al., 2001), we included these variables in our study. Gender was dummy-coded $(1=$ male, 2 = female $)$, age was selfreported in years and organizational tenure was self-reported in months. Network size represents the total number of people identified by each participant in the ego-network question (from 0 to 10). In line with previous research on international assignments (e.g., Van der Heijden et al., 2009), time on assignment was measured in terms of the months respondents had already been in their inpatriate assignment. To control for the possibility that inpatriates' links with HQ staff were established prior to their assignments, we measured the number of previous $H Q$ visits of the inpatriate before inpatriation. Given that the inpatriates in our study came from a wide variety of countries-of-origin, we also accounted for the effect of national culture. To do so, we used the respective scores of inpatriates' home-country culture for each of Hofstede and Hofstede's (2005) four cultural dimensions (power distance, individualism, masculinity and uncertainty avoidance). Finally, we constructed a three-item scale to measure inpatriates’ German language fluency $(\alpha=.95)$. An example item is "Please state the level of your German language proficiency in work-related interactions” $(1=$ very basic to 7 = fluent $)$. We included German language fluency as a control variable when testing our hypotheses to partial out the effect that lack of German language fluency may have on one’s ability to develop links with colleagues, acquire firm-specific knowledge, and perceive career prospects in the German MNC.

In addition to language fluency, we also considered controlling for the respondent's choice of survey language. We conducted t-tests comparing the means of the German and English responses to our five substantive continuous variables. We only found a significant difference in means for our measure of perceived career prospects ( $t=2.56, p<.05)$, with respondents completing the survey in German showing a significantly higher mean (mean = 5.65 and 4.89, for German and English respondents, respectively). Similarly, we conducted Chi-square tests for our two dichotomous endogenous variables, two-year and four-year retention, but did not find any significant differences. Given the significant mean differences for 
perceived career prospects, we therefore include choice of survey language as a control $(1=$ English, 2 = German). Finally, to account for possible effects of industry affiliation we constructed 5 dummy variables to represent the five different industries, using the pharmaceutical industry as the excluded, comparison, category.

We also examined possible response differences with regard to inpatriates' affiliation with any of the ten companies. Accordingly, we computed the intraclass coefficient scores for each of our two continuous endogenous variables to test whether they are subject to significant systematic between-group variance (Bliese \& Hanges, 2004). The ICC(1) scores have values of -.056 and -.003 (perceived career prospects, and firm-specific learning, respectively). Similarly, we conducted Chi-square tests for our two dichotomous endogenous variables, two-year retention $\left(\chi^{2}=13.15, d f=9, p>.05\right)$ and four-year retention $\left(\chi^{2}=9.70, d f=9, p>.05\right)$. Overall, the results suggest that nonindependence among the observations with regard to company affiliation is unlikely to be an issue in our study.

\section{RESULTS}

\section{Preliminary Analyses}

To evaluate the discriminant validity of all variables measured on the survey (ties to higher-level managers, average trust in network, fit with HQ, inpatriate learning, perceived career prospects) we first conducted a series of confirmatory factor analyses with AMOS (Arbuckle \& Wothke, 1999). As shown in Table 1, the fit indices reveal that the hypothesized five-factor model fit moderately well and, importantly, was significantly better fitting than any of the alternative nested models, indicating support for the distinctiveness of the constructs in the study.

Insert Table 1 about here

To test for common method bias, we conducted another confirmatory factor analysis in which all scale items were indicators of their respective theoretical latent factor as well as a single, unmeasured 
latent factor (Podsakoff, MacKenzie, Lee, \& Podsakoff, 2003). We had to use the full set of survey respondents ( $n=260$ after eliminating cases with missing data) to conduct these analyses in order to achieve model identification. We then compared the five-factor model without the latent common methods factor $\left(\chi^{2}=272.9, d f=95\right)$ with the measurement model including the common methods factor $\left(\chi^{2}=260.2, d f=80\right)$. The decrease in $\chi^{2}\left(\Delta \chi^{2}=-12.7, \Delta d f=15, p>.05\right)$ was insignificant, suggesting that the addition of the latent common methods factor did not significantly improve the fit of the measurement model. In addition, all factor loadings of the measurement model remained significant.

Table 2 reports means, standard deviations and correlations among the variables in the study, including all controls. In our regression analyses, we only include the control variables that are significantly correlated with the endogenous variables in our sample or that were statistically significant in preliminary regression equations that included all control variables (two of the industry dummy variables were significant in this analysis). By eliminating control variables uncorrelated with the endogenous variables we avoid potential spurious effects that controls may have when they are significantly related to the predictor, but not the criterion variables (i.e., we decrease Type I error), and we do not unnecessarily reduce our statistical power (Becker, 2005). All hypotheses were tested using the 143 respondents for whom retention data were available.

Insert Table 2 about here

\section{Tests of Hypotheses}

To test Hypotheses 1-4, we conducted two hierarchical regression analyses: one for inpatriate learning and one for perceived career prospects. In both regression equations, the control variables were entered in step one, and links with HQ colleagues (ties to higher-level managers and average trust in network) and fit with the HQ were entered in step two. As shown in Table 3, Model 2, both average trust in network (inpatriates’ links) and fit with HQ were positively related to inpatriate learning over and 
above the controls. At the same time, ties to higher-level managers, our other measure of inpatriates' links, was not significantly related to learning. Similarly, Model 4 of Table 3 reveals that both inpatriates' trust towards HQ colleagues and their fit with the HQ were positively related to inpatriates’ perceived career prospects whereas the effect of ties to higher-level managers was insignificant. Overall, these findings partially support Hypotheses 1 and 2 and fully support Hypotheses 3 and 4.

Insert Table 3 about here

Hypotheses 5 to 7 were tested together following the procedure described by Baron and Kenny (1986). We used logistic regression because retention is a dichotomous variable. We regressed inpatriate retention onto ties to higher-level managers, average trust, and fit with HQ along with the control variables (entered in step one) and the hypothesized mediator, perceived career prospects (entered in step two). Step one of tests for mediation is to show that the independent variables relate to the dependent variable. As shown in Table 4, Model 1, and Table 5, Model 1, inpatriates' fit with HQ positively related to both two-year and four-year retention whereas ties to higher-level managers and average trust in network (inpatriates' links) did not. Step two for tests of mediation aims to show that the independent variables relate to the mediator. The hierarchical regression results reported earlier indicated that average trust in network and fit with HQ positively related to perceived career prospects. Step three of mediation is to show that the mediator affects the dependent variable. In Table 4, Model 2, and Table 5, Model 2, we can see that perceived career prospects positively related to two-year and four-year retention when the independent variables are taken into account. Finally, for full mediation we need to show that the predictor is no longer related to the dependent variable when the mediator is in the equation. Model 2 in Tables 4 and 5 shows that fit with HQ was no longer significantly related to retention once we added in perceived career prospects. These results support Hypotheses 5 and $6 \mathrm{~b}$. 
Insert Table 4 about here

Scholars have recently questioned the need to show step one in establishing whether a significant mediation effect exists. As the mediation process becomes temporally more distal (as in the present case), the size of the association between the independent and the dependent variables may become smaller due to the potential of additional links in the causal chain, introduction of competing causal mechanisms, or random effects (Shrout \& Bolger, 2002). In our case, it is possible that inpatriates' trust towards HQ colleagues influences their retention through their perceived career prospects even though there is no direct effect on the dependent variable. To account for this possibility, it has been recommended to investigate mediation analyses based on formal significance tests of the indirect effect. Whereas this analysis is commonly conducted using the Sobel (1982) test, it rests on the assumption that the indirect effect of the independent on the dependent variable is normally distributed, an assumption that is tenuous with logistic regression (Preacher \& Hayes, 2004). Therefore, the computation of bootstrapped confidence intervals (CIs) is recommended as this avoids power problems introduced by asymmetric and other nonnormal sampling distributions of an indirect effect (MacKinnon, Lockwood, \& Williams, 2004). Accordingly, we complemented the Sobel (1982) test with bootstrapped CIs using an application provided by Preacher and Hayes (2004). The formal two-tailed significance test demonstrated a significant indirect effect of inpatriates' trust towards HQ colleagues on their two-year (Value $=.03, S E=.01$, Sobel $z=2.81$, $p<.01$ ) and four-year retention (Value $=.04, S E=.01$, Sobel $z=2.52, p<.05$ ). Bootstrap results (Bootstrap sample size $=5,000$ ) confirmed the Sobel test, with a bootstrapped 95\% CI around the indirect effect not containing zero (two-year retention: .01, .07; four-year retention: .01, .07). These results suggest that Hypothesis 6a was partially supported: Inpatriates' links to HQ colleagues in the form of trust indirectly related to inpatriate retention through their perceived career prospects.

Finally, Hypothesis 7 asserts that inpatriate learning moderates the relationship between inpatriates' perceived career prospects and their retention. We tested this hypothesis using moderated 
logistic regression in which we entered the control variables, the links and fit variables, perceived career prospects, and inpatriate learning in step one, and the interaction term for perceived career prospects $\times$ inpatriate learning in step two. We used the centered scores for each component of the interaction term to reduce multicollinearity (Aiken \& West, 1991). As shown in Model 3 of Table 4, the interaction term is negative and significant in predicting two-year retention. We probed the nature of the significant interaction effect by plotting the relationship between perceived career prospects and two-year retention at high and low levels of inpatriate learning (one standard deviation above and below mean, see Figure 2). To conduct simple slope tests in moderated logistic regression, we used an application provided by Hayes and Matthes (2009). The analysis revealed that perceived career prospects is positively related to inpatriate retention when inpatriate learning is low $(b=1.83, p<.01)$, but not significantly related to retention when inpatriate learning is high $(b=.65, p>.05)$. With regard to four-year retention, as shown in Model 3, Table 5, the interaction term was not statistically significant when entered in the regression equation. Thus, our results support Hypothesis 7 for retention two years later, but not four years later.

Insert Figure 2 about here

\section{DISCUSSION AND CONCLUSION}

Our study has highlighted some of the factors that influence inpatriate retention in MNCs. In particular, the results suggest that inpatriates' trusting links with HQ staff and their fit with the HQ positively related to their firm-specific learning and their perceived career prospects, and that the latter predicted their retention two and four years later. In this regard, perceived career prospects mediated the direct relationship between inpatriates' fit with the HQ and inpatriate retention as well as the indirect relationship between inpatriates' trust with HQ staff and their retention. Furthermore, we found that inpatriates' firm-specific learning during the assignment mitigates the effect of perceived career prospects on retention decisions two years later. 


\section{Theoretical Implications}

Our study contributes to the organizational embeddedness, careers, and international business literatures. With regard to organizational embeddedness, we built on Ng and Feldman's (2007) concept and applied it to the inpatriate context. Whereas scholars have considered various sources of embeddedness that include the job, the organization, the community and the occupation (Feldman \& Ng, 2007; Lee et al., 2004; Mitchell et al., 2001; Ng \& Feldman, 2007), existing research has thus far been primarily interested in the aggregate level of embeddedness. In contrast, our study focused on the concept's specific elements and their interrelations and proposed three theoretical mechanisms through which the dimensions of organizational embeddedness relate to retention. Drawing from social resources and social identity theories, we proposed an underlying set of relations in which an individual's links and fit relate to the sacrifices that are associated with leaving the organization. Our results provided support for this claim, demonstrating that inpatriates’ links with HQ staff and their fit with the HQ positively related to two specific costs of leaving: giving up the benefits associated with learning of firm-specific knowledge and perceived career prospects. Further, based on social exchange theory arguments, we found that a future-related sacrifice serves as a mediator for the relationship between inpatriates' links and fit, and their retention. Firm-specific learning served as an indirect sacrifice of leaving the organization by moderating the relationship between inpatriates’ perceived career prospects and two-year retention.

Our results for the effects of links on retention are consistent with social resources theory in that they mainly unfold through more immediate variables. In this vein, it appears that interpersonal trust may only serve as a retention mechanism for assignees if they feel that their trust building at the host unit is associated with continuous future benefits in the form of career prospects. The finding that ties to higherlevel managers at the HQ did not relate to learning or perceived career prospects was surprising given that past domestic research has demonstrated a positive effect on access to information and career sponsorship (e.g., Seibert et al., 2001). In the international assignment context it is possible that, given the ethnocentric biases inpatriates may face at the HQ (Harvey et al., 2005), senior managers at HQs may only be willing 
to provide inpatriates with such social resources if they have developed trusting relationships. In contrast, inpatriates’ fit with the HQ was shown to be directly related to inpatriate retention, suggesting that social identity-based mechanisms of retention have a more enduring character in binding assignees to the company. We may assume that this is because, once established, shared values are more stable than social resources, which are dependent on specific individuals in the organization.

Additionally, we contribute to social exchange theory by differentiating between past and future sources of costs and benefits that are associated with remaining in the organization. We proposed that this distinction may explain why individuals will be motivated to remain in the organization when they had acquired firm-specific knowledge or, in cases where they did not acquire a great deal of firm-specific knowledge, when they perceived future career prospects within the organization. Our findings indeed show that firm-specific learning may compensate for a lack of perceived career prospects, although only within a two-year time period, thus providing some support that past investments indirectly predict retention. We speculate that our contention did not hold for four-year retention because, over time, inpatriates' firm-specific learning during their assignments may become less useful as inpatriates move onto other jobs and/or have to adapt to changing demands of their jobs. However, our inconsistent results for the moderating effect across the two time periods should be interpreted with caution given the small number of leavers after two years. Future research should more explicitly test social exchange theory explanations for why these variables may substitute for each other in predicting retention at multiple points in time.

We also contribute to the careers literatures by introducing two specific career-related forces that may motivate employees to stay with the organization. First, we provided empirical evidence that perceived career prospects predicted retention two and four years later. Although turnover theories have alluded to the notion that promotional opportunities may motivate employees to remain in the organization either as a sacrifice for leaving (Mitchell et al., 2001) or for rational, calculative reasons (Maertz \& Campion, 2004), few studies have directly examined the role of career prospects in predicting retention, as opposed to turnover intentions (e.g., Bigliardi et al., 2005; Chay \& Aryee, 1999; Stahl et al., 2009; Van 
der Heijden et al., 2009), as we did here. The second factor we introduced, learning of firm-specific knowledge, moderated the positive effects of perceived career prospects on two-year retention such that the relationship was only significant when inpatriates’ learning was low. This finding may help explain why previous researchers have not found a significant relationship between expatriates' internal career prospects and turnover intentions (Stahl et al., 2009; Van der Heijden et al., 2009): at least in the shortterm, it appears that the firm-specific learning associated with international assignments may compensate for a lack of perceived career prospects. Although research has examined “general” knowledge development (e.g., participation in tuition reimbursement programs) as predictors of turnover (Benson, Finegold, \& Mohrman, 2004), we are not aware of research that has considered how developing firmspecific human capital relates to turnover or retention. Our findings suggest that career-related issues, in general, may play an important role in retention decisions especially for managerial and professional workers.

Finally, we contribute to the international business literature. A major axiom of the international assignment literature is that MNCs need to provide career advancement opportunities upon completion of the transfer to retain assignees (Feldman \& Thomas, 1992; Kraimer, Shaffer, \& Bolino, 2009; Lazarova \& Caligiuri, 2001). To that end, our study is unique in examining whether assignees’ perceived career prospects actually predict retention. The finding that inpatriates' trust with HQ staff only indirectly affected inpatriate retention through their perceived career prospects indicates that repatriation and career support may be even more important for retaining international staff than previously assumed. Through our collection of actual turnover data we also empirically contribute to the prevailing debate about the extent and nature of assignee turnover rates (cf., Harzing \& Christensen, 2004). Since all respondents in our study had completed their assignments four years after initial data collection, our study suggests an inpatriate turnover rate of $16 \%$ within the first four years after completing the HQ assignment. Although few, if any, studies provide reliable turnover rates for returning expatriates, estimates based on the 2010 Global Relocation Trends Report (Brookfield Global Relocation Services, 2010) suggest that it might be 
as high as $61 \%$ within the first two years. Further research that collects actual voluntary turnover data among repatriated employees is clearly needed to help to resolve this debate.

Our findings also have implications concerning the key motives for MNCs to use international assignments as a staffing strategy. First, whereas research has highlighted the role of international transfers as a means to develop international competencies (Edström \& Galbraith, 1977; Gregersen et al., 1998), the majority of studies have focused on generic competencies such as global business acumen and intercultural skills (e.g., Furuya et al., 2009) rather than firm-specific knowledge as we do. Second, international assignees have also long been regarded as conduits of MNC knowledge flows. However, our understanding of how such knowledge flows occur at the individual level of analysis (Foss \& Pedersen, 2004) and how assignees acquire the knowledge that they can subsequently diffuse to the wider organization (Reiche et al., 2009) remains fairly limited. Our research suggests that there are at least two critical variables that influence assignees' acquisition of knowledge in the host unit. If assignees develop links with host-unit staff and share values with the host unit, they are more likely to acquire firm-specific knowledge which they can potentially further diffuse in the MNC upon completion of their assignments. Moreover, the finding that fit with the host unit in particular has a direct effect on assignee retention suggests that this variable not only enables firm-specific learning during the assignment but, given its role for retention, can also facilitate on-going learning and knowledge sharing after the assignee returns home (see Vora \& Kostova, 2007). The relevance of shared values in MNCs as highlighted by Nohria and Ghoshal (1994) thus seems to also translate into individual-level benefits.

\section{Managerial Implications}

Our study has several implications for managerial practice. First, the finding that inpatriates’ fit with the HQ constitutes an important determinant for their retention suggests that socialization is important for international assignees. One way for MNCs to achieve this is to more explicitly offer induction programs prior to, and ongoing training and social activities during, the relocation. Also, given the risk of ethnocentric stigmatization towards inpatriates at the HQ and the likely negative effects on 
inpatriates' development of links at the HQ, HQ staff needs to be actively involved in the inpatriation process and be provided with cross-cultural training. In addition, the role of fit with the HQ emphasizes the selection of individuals for inpatriation based on value congruence. Research suggests that newcomers with a higher level of organization fit in terms of shared values and goals at the time of entry will more quickly adjust to their new environment (Chatman, 1991). For MNCs to benefit from their international staff in the long run, the selection of candidates for international transfers thus needs to move beyond the focus on technical skills that still dominates corporate practice (Harris \& Brewster, 1999).

Second, the literature has pointed to a lack of adequate positions available to international assignees upon their repatriation as a reason for high turnover rates among repatriates (e.g., Kraimer et al., 2009). Our results suggest that inpatriates may be more likely to continue their membership, at least for two years, irrespective of their perceived career opportunities if they have acquired firm-specific knowledge. Accordingly, companies need to offer assignees rich learning opportunities that provide them with tacit knowledge about the firm. Moreover, whereas many companies plan and conduct international transfers on an ad hoc basis, such an approach fails to capitalize on the long-term benefits that result from a firm's ability to both facilitate assignees' development of social ties during the assignment and, given the retention capacity of such links, maintain this social capital in the long run. For example, former inpatriates may continue to access HQ-specific knowledge through the social relationships developed during their HQ posting, thereby making them more effective in future positions within the MNC. As a result, organizational managers need to embed staff transfers into logical career paths that are consistent with the long-term goals of both the company and the individual assignee.

Finally, our findings suggest that MNCs would benefit from using host-country mentors to support inpatriate transfers (see Mezias \& Scandura, 2005). First, mentors at the HQ may help inpatriates to better assess their career prospects within the larger organization, which may ensure retention of those individuals that are most valuable to the MNC. Second, host-country mentors could also be instrumental in sharing their own social relationships with inpatriates, thereby enabling the latter to develop more farreaching links themselves. In particular, a host-country mentor may signal to other HQ staff that the 
inpatriate mentee can be trusted, which may facilitate inpatriates' development of trusting ties at the HQ. Third, host-country mentors that provide career support (such as challenging jobs and job coaching) may help the inpatriate learn firm-specific knowledge (Lankau \& Scandura, 2002).

\section{Limitations and Future Research}

Our study's contributions have to be considered in the context of its limitations. A first limitation concerns the use of self-report data for the assessment of our variables and the inherent sources of bias in respondents' perceptions. For example, there is evidence that individuals tend to over- or under-report certain characteristics of their ego networks (Casciaro, 1998). Similarly, our measure of fit to the HQ is subjective and does not capture the actual organizational values of the HQ. In addition, the finding that ties to higher-level managers at the HQ did not relate to learning or perceived career prospects may also be due to the narrower scope of this measure. Although our focus on ties to higher-level managers is consistent with previous social network research (e.g., Seibert et al., 2001), we encourage future research to include multiple structural characteristics of assignees' links to host-unit staff to more broadly capture the links dimension of organizational embeddedness. A second limitation refers to the relatively small number of leavers after two years, which may affect the stability of our parameter estimates and may explain why we did not find a significant interaction effect between perceived career prospects and firmspecific learning with regard to four-year retention. It is thus difficult to determine whether the difference in results for the interaction effect is due to theoretical reasons or to the added stability of the four-year turnover data. However, because a low base rate of a dichotomous dependent variable reduces the power to detect statistically significant effects (Harrison, 2001), we would argue that our two-year retention data, compared to the four-year retention data, provides a conservative test of the hypothesized moderation suggesting there are theoretical reasons for why the interaction effect was significant in predicting twoyear, but not four-year, retention.

A third limitation is the potential of common method bias, which can inflate relationships among variables. Several measures were taken to minimize this risk, including the combination of ego-network 
and perception-based question formats, the separation of items for the independent and dependent variables into different sections of the questionnaire, and the use of different scale endpoints. To further address this issue, we had also measured inpatriates' perceived career prospects in a follow-up survey two years later (about the same time we collected the two-year retention data from company records). When we regressed the Time 2 measure of perceived career prospects onto the two links and fit variables measured at Time 1, we found that average trust in HQ staff and fit with the HQ were significantly, positively $(\mathrm{p}<.01)$ related to perceived career prospects at Time 2 , thereby replicating the cross-sectional results and providing additional evidence that common method bias is unlikely to be a major concern in this study. This analysis based on longitudinal data also provides further support for our mediation hypothesis that the links and fit dimensions of organizational embeddedness lead to benefits that would be sacrificed if one left the firm. Despite these measures, we acknowledge that common method bias cannot be completely ruled out in this study.

One possible way to extend our research would be to include inpatriates' HQ contacts in the analysis and examine more directly how HQ staff perceptions and attitudes affect inpatriates' development of links at the HQ. It is possible that social ties that are not reciprocated by inpatriates’ HQ colleagues reduce the role of inpatriates' organizational embeddedness. Future research may adopt our findings as a guideline and re-focus the analysis on a single organization, using an in-depth case study design to more closely investigate multiple perceptions and the degree of reciprocity of inpatriates' network ties with HQ staff. It would also be interesting to consider assignees' embeddedness in the larger community and its differential career effects. For example, inpatriates may attempt to leverage their social ties at the HQ for employment benefits outside the organization to remain in the assignment country upon completion of their posting, thereby avoiding a return to their home country and a resulting decrease in salary and/or living standards. This is particularly relevant for inpatriates from less developed countries.

Future research could also study in more detail the conditions under which organizations may benefit from their assignees in the long run. Recent research has criticized the well-established assumption that retention upon repatriation automatically benefits the larger organization (Lazarova \& Cerdin, 2007). 
We would contend that organizations can only make use of the social ties and knowledge inpatriates have acquired during the assignment, if assignees are willing to apply these in organizationally useful ways. For example, inpatriates may connect their newly developed social ties at the HQ with colleagues at their home subsidiary, thereby initiating continued cross-unit knowledge flows. However, doing so may eliminate the brokerage position inpatriates occupy between their social networks at the HQ and the home subsidiary (Burt, 1992), thereby reducing their unique value for the MNC.

In sum, by integrating the literatures on organizational embeddedness, careers and international assignments, the relationships tested in this study extend our theoretical and empirical understanding of what determines inpatriate retention in MNCs. In this vein, the concept of organizational embeddedness provides a fruitful lens to examine the international assignment process and assignees' retention decisions. 


\section{REFERENCES}

Aiken, L. S., \& West, S. G. 1991. Multiple regression: Testing and interpreting interactions. Thousand Oaks, CA: Sage.

Arbuckle, J. L., \& Wothke, W. 1999. Amos 4.0 user's guide. Chicago, IL: SmallWaters Corporation.

Ashforth, B. E., \& Mael, F. 1989. Social identity theory and the organization. Academy of Management Review, 14(1): 20-39.

Ashforth, B. E., Harrison, S. H., \& Corley, K. G. 2008. Identification in organizations: An examination of four fundamental questions. Journal of Management, 34(3): 325-374.

Barner-Rasmussen, W. 2003. Determinants of the feedback-seeking behaviour of subsidiary top managers in multinational corporations. International Business Review, 12(1): 41-60.

Baron, R. M., \& Kenny, D. A. 1986. The moderator-mediator variable distinction in social psychology research: Conceptual, strategic, and statistical considerations. Journal of Personality and Social Psychology, 51(6): 1173-1182.

Becker, T. E. 2005. Potential problems in the statistical control of variables in organizational research: A qualitative analysis with recommendations. Organizational Research Methods, 8(3): 274-289.

Benson, G. S., Finegold, D., \& Mohrman, S. A. 2004. You paid for the skills, now keep them: Tuitionreimbursement and voluntary turnover. Academy of Management Journal, 47(3): 315-331.

Bhagat, R. S., Kedia, B. L., Harveston, P. D., \& Triandis, H. C. 2002. Cultural variation in the crossborder transfer of organizational knowledge: An integrative framework. Academy of Management Review, 27(2): 204-221.

Bian, Y. 1997. Bringing strong ties back in: Indirect ties, network bridges, and job searches in China. American Sociological Review, 62(3): 366-385.

Bigliardi, B., Petroni, A., \& Dormio, A. I. 2005. Organizational socialization, career aspirations and turnover intentions among design engineers. Leadership \& Organization Development Journal, 26(6): 424-441.

Björkman, I., Barner-Rasmussen, W., \& Li, L. 2004. Managing knowledge transfer in MNCs: The impact of headquarters control mechanisms. Journal of International Business Studies, 35(5): 443-455.

Blau, P. M. 1964. Exchange and power in social life. New York: Wiley.

Bliese, P. D., \& Hanges, P. J. 2004. Being both too liberal and too conservative: The perils of treating grouped data as though they were independent. Organizational Research Methods, 7(4): 400-417.

Borgatti, S. P., \& Cross, R. 2003. A relational view of information seeking and learning in social networks. Management Science, 46(4): 432-445. 
Bretz, R. D. Jr, \& Judge, T. A. 1994. Person-organization fit and the theory of work adjustment: Implications for satisfaction, tenure, and career success. Journal of Vocational Behavior, 44(1): $32-54$.

Brislin, R. W. 1970. Back-translation for cross-cultural research. Journal of Cross-Cultural Psychology, 1(3): 185-216.

Brookfield Global Relocation Services. 2010. Global relocation trends: 2010 survey report. Toronto, Canada.

Burt, R. S. 1992. Structural holes: The social structure of competition. Cambridge, MA: Harvard University Press.

Casciaro, T. 1998. Seeing things clearly: Social structure, personality, and accuracy in social network perceptions. Social Networks, 20(4): 331-351.

Chatman, J. A. 1991. Matching people and organizations: Selection and socialization in public accounting firms. Administrative Science Quarterly, 36(3): 459-484.

Chay, Y., \& Aryee, S. 1999. Potential moderating influence of career growth opportunities on careerist orientation and work attitudes: evidence of the protean career era in Singapore. Journal of Organizational Behavior, 20(5): 613-623.

Coff, R. W. 1997. Human assets and management dilemmas: Coping with hazards on the road to resource-based theory. Academy of Management Review, 22(2): 374-402.

Cross, R, \& Cummings, J. N. 2004. Tie and network correlates of individual performance in knowledgeintensive work. Academy of Management Journal, 47(6): 928-937.

Edström, A., \& Galbraith, J. R. 1977. Transfer of managers as a coordination and control strategy in multinational organizations. Administrative Science Quarterly, 22(2): 248-263.

Erdogan, B., Kraimer, M. L., \& Liden, R. C. 2004. Work value congruence and intrinsic career success: The compensatory roles of leader-member exchange and perceived organizational support. Personnel Psychology, 57(2): 305-332.

Farh, C. I. C., Bartol, K. M., Shapiro, D. L., \& Shin, J. 2010. Networking abroad: A process model of how expatriates form support ties to facilitate adjustment. Academy of Management Review, 35(3): 434-454.

Feldman, D. C., \& Ng, T. W. H. 2007. Careers: Mobility, embeddedness, and success. Journal of Management, 33(3): 350-377.

Feldman, D. C., \& Thomas, D. C. 1992. Career management issues facing expatriates. Journal of International Business Studies, 23(2): 271-293.

Foss, N. J. \& Pedersen, T. 2004. Organizing knowledge processes in the multinational corporation: An introduction. Journal of International Business Studies, 35(5): 340-349. 
Furuya, N., Stevens, M. J., Bird, A., Oddou, G., \& Mendenhall, M. 2009. Managing the learning and transfer of global management competence: Antecedents and outcomes of Japanese repatriation effectiveness. Journal of International Business Studies, 40(2): 200-215.

Granovetter, M. S. 1973. The strength of weak ties. American Journal of Sociology, 78(6): 1360-1380.

Granrose, C. S., \& Portwood, J. D. 1987. Matching individual career plans and organizational career management. Academy of Management Journal, 30(4): 699-720.

Gregersen, H. B, Morrison, A. J, \& Black, J. S. 1998. Developing leaders for the global frontier. Sloan Management Review, 40(1): 21-32.

Hansen, M. T. 1999. The search-transfer problem: The role of weak ties in sharing knowledge across organization subunits. Administrative Science Quarterly, 44(1): 82-111.

Harris, H., \& Brewster, C. 1999. The coffee-machine system: How international selection really works. International Journal of Human Resource Management, 10(3): 488-500.

Harrison, D. A. 2001. Structure and timing in limited range dependent variables: Regression models for predicting if and when. In F. Drasgow \& N. Schmitt (Eds), Measuring and analyzing behavior in organizations: Advances in measurement and data analysis: 531-568. San Francisco: Jossey-Bass.

Harvey, M., Novicevic, M. M., Buckley, M. R., \& Fung, H. 2005. Reducing inpatriate managers' 'liability of foreignness' by addressing stigmatization and stereotype threats. Journal of World Business, 40(3): 267-280.

Harvey, M., Novicevic, M. M., \& Speier, C. 1999. Inpatriate managers: How to increase the probability of success. Human Resource Management Review, 9(1): 51-81.

Harzing, A.-W., \& Christensen, C. 2004. Expatriate failure: Time to abandon the concept? Career Development International, 9(7): 616-626.

Hayes A. F., \& Matthes J. 2009. Computational procedures for probing interactions in OLS and logistic regression: SPSS and SAS implementations. Behavior Research Methods. 41(3): 924-936.

Heslin, P. A. 2005. Conceptualizing and evaluating career success. Journal of Organizational Behavior, 26(2): 113-136.

Hocking, J. B., Brown, M. E., \& Harzing, A.-W. 2007. Balancing global and local strategic contexts: Expatriate knowledge transfer, applications and learning within a transnational organization. Human Resource Management, 46(4): 513-533.

Hofstede, G., \& Hofstede, G. J. 2005. Cultures and organizations: Software of the mind (2nd ed.). New York: McGraw-Hill.

Holtom, B. C., Mitchell, T. R., Lee, T. W., \& Eberly, M. B. 2008. Turnover and retention research: A glance at the past, a closer review of the present, and a venture into the future. Academy of Management Annals, 2: 231-274. 
Hom, P. W., Boudwin, K., \& Allen, D. G. 2009. Social network theory and job embeddedness. Proceedings of the Southern Management Association of the Academy of Management Annual Meetings, Asheville, NC.

Homans, G. C. 1961. Social behavior. New York: Harcourt, Brace and World.

Judge, T. A., Cable, D. M., Boudreau, J. W., \& Bretz, R. D. Jr. 1995. An empirical investigation of the predictors of executive career success. Personnel Psychology, 48(3): 485-519.

Kane, A. A., Argote, L., \& Levine, J. M. 2005. Knowledge transfer between groups via personnel rotation: Effects of social identity and knowledge quality. Organizational Behavior and Human Decision Processes, 96(1): 56-71.

Kostova, T. \& Roth, K. 2002. Adoption of an organizational practice by subsidiaries of multinational corporations: Institutional and relational effects. Academy of Management Journal, 45(1): 215233.

Kostova, T., \& Roth, K. 2003. Social capital in multinational corporations and a micro-macro model of its formation. Academy of Management Review, 28(2): 297-317.

Kraimer, M. L., Shaffer, M. A., \& Bolino, M. C. 2009. The influence of expatriate and repatriate experiences on career advancement and repatriation retention. Human Resource Management, 48(1): 27-47.

Lankau, M. J. \& Scandura, T. A. 2002. An Investigation of Personal Learning in Mentoring Relationships: Content, Antecedents, and Consequences. Academy of Management Journal, 45(4): 779-790.

Lazarova, M., \& Caligiuri, P. 2001. Retaining repatriates: The role of organizational support practices. Journal of World Business, 36(4): 389-401.

Lazarova, M., \& Cerdin, J. L. 2007. Revisiting repatriation concerns: Organizational support versus career and contextual influences. Journal of International Business Studies, 38(3): 404-429.

Lee, T. W., Mitchell, T. R., Sablynski, C. J., Burton, J. P., \& Holtom, B. C. 2004. The effects of job embeddedness on organizational citizenship, job performance, volitional absences, and voluntary turnover. Academy of Management Journal, 47(5): 711-722.

Lin, N., Ensel, W. M., \& Vaughn, J. C. 1981. Social resources and strength of ties: Structural factors in occupational status attainment. American Sociological Review, 46(4): 393-405.

Liu, X., \& Shaffer, M. A. 2005. An investigation of expatriate adjustment and performance: A social capital perspective. International Journal of Cross-Cultural Management, 5(3): 235-254.

Louis, M. R. 1980. Surprise and sense making: What newcomers experience in entering unfamiliar organizational settings. Administrative Science Quarterly, 25(2): 226-251.

Lyness, K. S., \& Thompson, D. E. 2000. Climbing the corporate ladder: Do female and male executives follow the same route? Journal of Applied Psychology, 85(1): 86-101. 
MacKinnon, D. P., Lockwood, C. M., \& Williams, J. 2004. Confidence limits for the indirect effect: Distribution of the product and resampling methods. Multivariate Behavioral Research, 39(1): 99-128.

Maertz, C. P., \& Campion, M. A. 2004. Profiles in quitting: Integrating process and content turnover theory. Academy of Management Journal, 47(4): 566-582.

Mäkelä, K., \& Brewster, C. 2009. Interunit interaction contexts, interpersonal social capital, and the differing levels of knowledge sharing. Human Resource Management, 48(4): 591-613.

Mardsen, P. V., \& Hurlbert, J. S. 1988. Social resources and mobility outcomes: A replication and extension. Social Forces, 66(4): 1039-1059.

Maurer, T. J., Weiss, E. M., \& Barbeite, F. G. 2003. A model of involvement in work-related learning and development activity: The effects of individual, situational, motivational, and age variables Journal of Applied Psychology, 88(4): 707-724.

Mendenhall, M., \& Oddou, G. 1985. The dimensions of expatriate acculturation: A review. Academy of Management Review, 10(1): 39-47.

Mezias, J. M., \& Scandura, T. A. 2005. A needs-driven approach to expatriate adjustment and career development: A multiple mentoring perspective. Journal of International Business Studies, 36(5): 519-538.

Mitchell, T. R., Holtom B. C., Lee, T. W., Sablynski, C. J., \& Erez, M. 2001. Why people stay: Using job embeddedness to predict voluntary turnover. Academy of Management Journal, 44(6): 11021121.

Ng, T. W. H., \& Feldman, D. C. 2007. Organizational embeddedness and occupational embeddedness across career stages. Journal of Vocational Behavior, 70(2): 336-351.

Nohria, N. \& Ghoshal, S. 1994. Differentiated fit and shared values: Alternatives for managing headquarters-subsidiary relations. Strategic Management Journal, 15(6): 491-502.

Oddou, G., Gregersen, H. B., Black, J. S., \& Derr, C. B. 2001. Building global leaders: Strategy similarities and differences among European, U.S., and Japanese multinationals. In M. E. Mendenhall, T. M. Kühlmann \& G. K. Stahl (Eds), Developing global leaders: Policies, processes, and innovations: 99-116. Westport: Quorum Books.

O'Reilly, C. A., Chatman, J., \& Caldwell, D. F. 1991. People and organizational culture: A profile comparison approach to assessing person-organization fit. Academy of Management Journal, 34(3): 487-516.

Podolny, J. M., \& Baron, J. N. 1997. Resources and relationships: Social networks and mobility in the workplace. American Sociological Review, 62(5): 673-693.

Podsakoff, P. M., MacKenzie, S. B., Lee, J. Y., \& Podsakoff, N. P. 2003. Common method biases in behavioral research: A critical review of the literature and recommended remedies. Journal of Applied Psychology, 88(5): 879-903. 
Preacher, K. J., \& Hayes, A. F. 2004. SPSS and SAS procedures for estimating indirect effects in simple mediation models. Behavior Research Methods, 36(4): 717-731.

Reade, C. 2001. Antecedents of organizational identification in multinational corporations: Fostering psychological attachment to the local subsidiary and the global organization. International Journal of Human Resource Management, 12(8): 1269-1291.

Reagans, R., \& McEvily, B. 2003. Network structure and knowledge transfer: The effects of cohesion and range. Administrative Science Quarterly, 48(2): 240-267.

Reiche, B. S. 2006. The inpatriate experience in multinational corporations: An exploratory case study in Germany. International Journal of Human Resource Management, 17(9): 1572-1590.

Reiche, B. S., Harzing, A. W., \& Kraimer, M. L. 2009. The role of international assignees’ social capital in creating inter-unit intellectual capital: A cross-level model. Journal of International Business Studies, 40(3): 509-526.

Shaffer, M. A., Harrison, D. A., \& Gilley, K. M. 1999. Dimensions, determinants, and differences in the expatriate adjustment process. Journal of International Business Studies, 30(3): 557-581.

Seibert, S. E., Kraimer, M. L., \& Liden, R. C. 2001. A social capital theory of career success. Academy of Management Journal, 44(2): 219-237.

Shen, Y., \& Hall, D. T. 2009. When expatriates explore other options: Retaining talent through greater job embeddedness and repatriation adjustment. Human Resource Management, 48(5): 793-816.

Shrout, P. E., \& Bolger, N. 2002. Mediation in experimental and nonexperimental studies: New procedures and recommendations. Psychological Methods, 7(4): 422-445.

Sobel, M. E. 1982. Asymptotic confidence intervals for indirect effects in structural equation models. In S. Leinhardt (Ed), Sociological methodology: 290-312. San Francisco: Jossey-Bass.

Stahl, G. K., Chua, C. H., Caligiuri, P., Cerdin, J. L., \& Taniguchi, M. 2009. Predictors of turnover intentions in learning-driven and demand-driven international assignments: The role of repatriation concerns, satisfaction with company support, and perceived career advancement opportunities. Human Resource Management, 48(1): 89-109.

Stahl, G. K., Miller, E. L., \& Tung, R. L. 2002. Toward the boundaryless career: A closer look at the expatriate career concept and the perceived implications of an international assignment. Journal of World Business, 37(3): 216-227.

Stroh, L. K., Gregersen, H. B., \& Black, J. S. 1998. Closing the gap: Expectations versus reality among repatriates. Journal of World Business, 33(2): 111-124.

Tharenou, P., \& Harvey, M. 2006. Examining the overseas staffing options utilized by Australian headquartered multinational corporations. International Journal of Human Resource Management, 17(6): 1095-1114.

Toh, S. M., \& DeNisi, A. S. 2007. Host country nationals as socializing agents: A social identity approach. Journal of Organizational Behavior, 28(3): 281-301. 
Tsai, W., \& Ghoshal, S. 1998. Social capital and value creation: The role of intrafirm networks. Academy of Management Journal, 41(4): 464-476.

Van der Heijden, J. A. V., van Engen, M. L., \& Paauwe, J. 2009. Expatriate career support: Predicting expatriate turnover and performance. International Journal of Human Resource Management, 20(4): 831-845.

Van de Vijver, F. J. R., \& Leung, K. 1997. Methods and data analysis for cross-cultural research. Thousand Oaks, CA: Sage.

Vora, D., \& Kostova, T. 2007. A model of dual organizational identification in the context of the multinational enterprise. Journal of Organizational Behavior, 28(3): 327-350.

Wang, X., \& Kanungo, R. N. 2004. Nationality, social network and psychological well-being: Expatriates in China. International Journal of Human Resource Management, 15(4-5): 775-793. 
TABLE 1. Results of Confirmatory Factor Analysis for the Survey Measures ${ }^{\text {a }}$

\begin{tabular}{lccccc}
\hline Model & $\chi^{2}$ & df & TLI & CFI & RMSEA \\
\hline Five-factor model & 172.18 & 95 & .91 & .94 & .08 \\
Four factor model: inpatriate learning and & 206.48 & 96 & .88 & .91 & .09 \\
perceived career prospects combined & & & & & \\
Three-factor model: links and fit combined & 236.55 & 98 & .85 & .89 & .10 \\
One-factor model & 289.28 & 105 & .81 & .86 & .11 \\
\hline
\end{tabular}

${ }^{a}$ TLI is the Tucker-Lewis index; CFI, the comparative fit index; and RMSEA, the root-mean-square error of approximation; $\mathrm{n}=143$. 
TABLE 2. Means, Standard Deviations and Correlations ${ }^{a}$

\begin{tabular}{|c|c|c|c|c|c|c|c|c|c|c|c|c|c|c|c|c|c|}
\hline Variable & Mean & SD & 1 & 2 & 3 & 4 & 5 & 6 & 7 & 8 & 9 & 10 & 11 & 12 & 13 & 14 & 15 \\
\hline 1 Links: Ties to higher-level managers & 2.73 & 1.63 & $\underline{\text { na }}$ & & & & & & & & & & & & & & \\
\hline 2 Links: Average trust in network & 5.05 & .92 & $-.18^{*}$ & .77 & & & & & & & & & & & & & \\
\hline 3 Fit with HQ & 5.21 & 1.19 & -.11 & $.24 * *$ & $\underline{.80}$ & & & & & & & & & & & & \\
\hline 4 Inpatriate learning & 5.91 & .89 & -.01 & $.22 *$ & $.19 *$ & $\underline{.86}$ & & & & & & & & & & & \\
\hline 5 Perceived career prospects & 5.01 & 1.34 & -.02 & $.28^{* *}$ & $.54^{* *}$ & $.19 *$ &.$\underline{.93}$ & & & & & & & & & & \\
\hline 6 Two-year retention & .92 & .28 & -.04 & $.18^{*}$ & $.37 * *$ & .02 & $.39 * *$ & $\underline{\text { na }}$ & & & & & & & & & \\
\hline 7 Four-year retention & .84 & .37 & .06 & .10 & $.24^{* *}$ & -.04 & $.31^{* *}$ & $.68^{* *}$ & na & & & & & & & & \\
\hline 8 Network size & 9.05 & 1.84 & $.28 * *$ & -.04 & .08 & .09 & -.06 & .04 & .00 & $\underline{\text { na }}$ & & & & & & & \\
\hline 9 Individualism (Hofstede) & 64.13 & 24.86 & -.12 & .06 & $-.20^{*}$ & -.12 & -.14 & -.02 & -.08 & -.06 & na & & & & & & \\
\hline 10 Power distance (Hofstede) & 55.23 & 18.28 & .07 & -.03 & $.27 * *$ & .11 & $.21^{*}$ & .11 & .11 & .04 & $-.79 * *$ & $\underline{\text { na }}$ & & & & & \\
\hline 11 Masculinity (Hofstede) & 57.35 & 15.75 & -.05 & $.19^{*}$ & -.04 & -.06 & .02 & .09 & .03 & .03 & .11 & .07 & $\underline{\text { na }}$ & & & & \\
\hline 12 Uncertainty avoidance (Hofstede) & 63.15 & 20.72 & .14 & .01 & $.26^{* *}$ & $.18^{*}$ & $.23 * *$ & .09 & .13 & .03 & $.55^{* *}$ & $.52 * *$ & -.13 & na & & & \\
\hline 13 Age & 37.36 & 6.50 & $-.34 * *$ & -.05 & -.11 & -.07 & -.11 & $-.17^{*}$ & -.07 & .05 & .12 & $-.18^{*}$ & .05 & $-.23 * *$ & $\underline{\text { na }}$ & & \\
\hline 14 Gender & 1.18 & .39 & .06 & .13 & -.01 & $-.21 *$ & -.01 & -.06 & -.09 & .03 & .06 & -.07 & -.04 & -.01 & -.09 & $\underline{\text { na }}$ & \\
\hline 15 Organizational tenure & 110.90 & 68.47 & $-.23 * *$ & .04 & -.02 & .08 & -.06 & -.15 & -.11 & .08 & .08 & -.11 & .12 & -.09 & $.60^{* *}$ & -.11 & na \\
\hline 16 Time on assignment & 24.02 & 18.40 & -.09 & .06 & $-.20^{*}$ & .15 & -.16 & -.15 & $-.20 *$ & .04 & $.17^{*}$ & $-.21^{*}$ & .00 & -.08 & $.40 * *$ & -.13 & $.43^{* *}$ \\
\hline 17 Number of previous HQ visits & 2.87 & 1.49 & -.09 & -.13 & .07 & .01 & -.05 & .01 & .00 & .04 & .09 & -.03 & -.00 & -.01 & .07 & -.04 & $.20^{*}$ \\
\hline 18 German language fluency & 4.30 & 1.96 & .02 & .02 & .04 & $.23 * *$ & .09 & .04 & -.03 & -.12 & .01 & .11 & .01 & $.30^{* *}$ & -.09 & -.02 & .09 \\
\hline 19 Survey language & 1.16 & .37 & .04 & -.02 & .07 & -.10 & $.20 *$ & -.10 & -.04 & -.15 & $-.23 * *$ & $.32 * *$ & .09 & $.40 * *$ & -.07 & .16 & -.04 \\
\hline 20 Automotive & .34 & .47 & $.22 *$ & .01 & -.01 & -.05 & .02 & .03 & .13 & -.06 & $-.21 * *$ & $.17^{*}$ & $.20 *$ & .09 & $-.23 * *$ & -.05 & -.15 \\
\hline 21 Aviation & .03 & .18 & -.15 & .03 & .02 & .09 & .02 & -.11 & -.04 & -.05 & -.01 & -.04 & .13 & -.08 & .05 & .03 & $.19 *$ \\
\hline 22 Banking & .03 & .18 & .02 & -.04 & .03 & -.14 & .05 & .04 & .05 & .06 & .02 & .01 & .01 & -.10 & .13 & -.06 & -.13 \\
\hline 23 Chemical & .20 & .40 & -.03 & -.15 & .12 & -.12 & .03 & .02 & -.11 & .11 & -.01 & .06 & $-.21 *$ & $.21 *$ & -.05 & -.02 & -.07 \\
\hline 24 Consumer goods & .06 & .23 & -.01 & .09 & .04 & -.01 & .03 & .07 & .02 & .03 & $.22 * *$ & $-.18 *$ & .07 & $-.18^{*}$ & -.12 & .12 & -.06 \\
\hline
\end{tabular}

${ }^{\mathrm{a}}$ Bold values = alpha coefficients; $\mathrm{n}=143$; means and standard deviations refer to Time 1, except for two-year retention which is from Time 2 and four-year retention which is from Time $3 .{ }^{*} \mathrm{p}<.05,{ }^{* *} \mathrm{p}<.01$ 
TABLE 2. Means, Standard Deviations and Correlations ${ }^{\text {a }}$ (continued)

\begin{tabular}{|c|c|c|c|c|c|c|c|c|c|c|c|}
\hline Variable & Mean & SD & 16 & 17 & 18 & 19 & 20 & 21 & 22 & 23 & 24 \\
\hline 1 Links: Ties to higher-level managers & 2.73 & 1.63 & & & & & & & & & \\
\hline 2 Links: Average trust in network & 5.05 & .92 & & & & & & & & & \\
\hline 3 Fit with HQ & 5.21 & 1.19 & & & & & & & & & \\
\hline 4 Inpatriate learning & 5.91 & .89 & & & & & & & & & \\
\hline 5 Perceived career prospects & 5.01 & 1.34 & & & & & & & & & \\
\hline 6 Two-year retention & .92 & .28 & & & & & & & & & \\
\hline 7 Four-year retention & .84 & .37 & & & & & & & & & \\
\hline 8 Network size & 9.05 & 1.84 & & & & & & & & & \\
\hline 9 Individualism (Hofstede) & 64.13 & 24.86 & & & & & & & & & \\
\hline 10 Power distance (Hofstede) & 55.23 & 18.28 & & & & & & & & & \\
\hline 11 Masculinity (Hofstede) & 57.35 & 15.75 & & & & & & & & & \\
\hline 12 Uncertainty avoidance (Hofstede) & 63.15 & 20.72 & & & & & & & & & \\
\hline 13 Age & 37.36 & 6.50 & & & & & & & & & \\
\hline 14 Gender & 1.18 & .39 & & & & & & & & & \\
\hline 15 Organizational tenure & 110.90 & 68.47 & & & & & & & & & \\
\hline 16 Time on assignment & 24.02 & 18.40 & $\underline{\text { na }}$ & & & & & & & & \\
\hline 17 Number of previous HQ visits & 2.87 & 1.49 & .07 & $\underline{\text { na }}$ & & & & & & & \\
\hline 18 German language fluency & 4.30 & 1.96 & $.24 * *$ & .04 &.$\underline{.95}$ & & & & & & \\
\hline 19 Survey language & 1.16 & .37 & -.04 & -.06 & $.40 * *$ & $\underline{\text { na }}$ & & & & & \\
\hline 20 Automotive & .34 & .47 & $-.30 * *$ & -.13 & .14 & $.27 * *$ & na & & & & \\
\hline 21 Aviation & .03 & .18 & -.01 & .13 & .05 & -.07 & -.12 & $\underline{\text { na }}$ & & & \\
\hline 22 Banking & .03 & .18 & -.10 & $-.19^{*}$ & $-.18^{*}$ & -.05 & -.08 & -.02 & $\underline{\text { na }}$ & & \\
\hline 23 Chemical & .20 & .40 & .03 & $.26^{* *}$ & .14 & -.02 & $-.36 * *$ & -.09 & -.06 & $\underline{\text { na }}$ & \\
\hline 24 Consumer goods & .11 & .46 & .05 & .06 & $-.31 * *$ & -.11 & $-.17 * *$ & -.04 & -.03 & -.13 & $\underline{\text { na }}$ \\
\hline
\end{tabular}

${ }^{a}$ Bold values = alpha coefficients; $\mathrm{n}=143$; means and standard deviations refer to Time 1, except for two-year retention which is from Time 2 and four-year retention which is from Time $3 .{ }^{*} \mathrm{p}<.05,{ }^{* *} \mathrm{p}<.01$ 
TABLE 3. Results of Regression Analysis of Inpatriate Learning and Perceived Career Prospects ${ }^{\mathrm{a}}$

\begin{tabular}{|c|c|c|c|c|c|c|c|c|}
\hline \multirow[b]{3}{*}{ Variable } & \multicolumn{4}{|c|}{ Inpatriate Learning } & \multicolumn{4}{|c|}{ Perceived Career Prospects } \\
\hline & \multicolumn{2}{|c|}{ Model 1} & \multicolumn{2}{|c|}{ Model 2} & \multicolumn{2}{|c|}{ Model 3} & \multicolumn{2}{|c|}{ Model 4} \\
\hline & $\boldsymbol{\beta}$ & $t$ & $\boldsymbol{\beta}$ & $t$ & $\boldsymbol{\beta}$ & $t$ & $\beta$ & $t$ \\
\hline Power distance (Hofstede) & .05 & .56 & .03 & .36 & .07 & .70 & .01 & .07 \\
\hline Uncertainty avoidance (Hofstede) & $.22 *$ & 2.13 & .18 & 1.75 & .12 & 1.10 & .02 & .24 \\
\hline Age & -.09 & -1.02 & -.07 & -.76 & -.01 & -.08 & .02 & .18 \\
\hline Gender & -.16 & -1.94 & $-.18^{*}$ & -2.22 & -.05 & -.56 & -.07 & -.89 \\
\hline Time on assignment & .12 & 1.30 & .13 & 1.43 & -.14 & -1.39 & -.07 & -.87 \\
\hline German language fluency & $.26^{* *}$ & 2.74 & $.25 * *$ & 2.72 & .03 & .26 & .01 & .12 \\
\hline Survey language & $-.26 * *$ & -2.71 & $-.24 *$ & -2.62 & .13 & 1.27 & .16 & 1.79 \\
\hline Aviation & .07 & .86 & .07 & .83 & .00 & .04 & .01 & .07 \\
\hline Chemical & $-.22 * *$ & -2.70 & $-.20 *$ & -2.47 & .04 & .49 & .03 & .40 \\
\hline Links: Ties to higher-level managers & & & .04 & .43 & & & .06 & .74 \\
\hline Links: Average trust in network & & & $.18^{*}$ & 2.15 & & & $.19 *$ & 2.44 \\
\hline Fit with HQ & & & $.17^{*}$ & 2.05 & & & $.47^{* *}$ & 5.83 \\
\hline$\Delta \mathrm{R}^{2}$ & \multicolumn{6}{|c|}{$.06^{*}$} & \multicolumn{2}{|c|}{$.27 * *$} \\
\hline $\mathrm{R}^{2}$ & \multicolumn{2}{|c|}{.22} & \multicolumn{2}{|c|}{.27} & \multicolumn{2}{|c|}{.10} & \multicolumn{2}{|c|}{.36} \\
\hline $\mathrm{F}$ & \multicolumn{2}{|c|}{$3.92 * *$} & \multicolumn{2}{|c|}{$3.90 * *$} & \multicolumn{2}{|c|}{1.53} & \multicolumn{2}{|c|}{$5.96^{* *}$} \\
\hline
\end{tabular}

${ }_{\mathrm{a}}^{\mathrm{n}}=143 .{ }^{*} \mathrm{p}<.05,{ }^{* *} \mathrm{p}<.01$ 
TABLE 4. Results of Logistic Regression Analysis of Inpatriate Two-Year Retention ${ }^{a}$

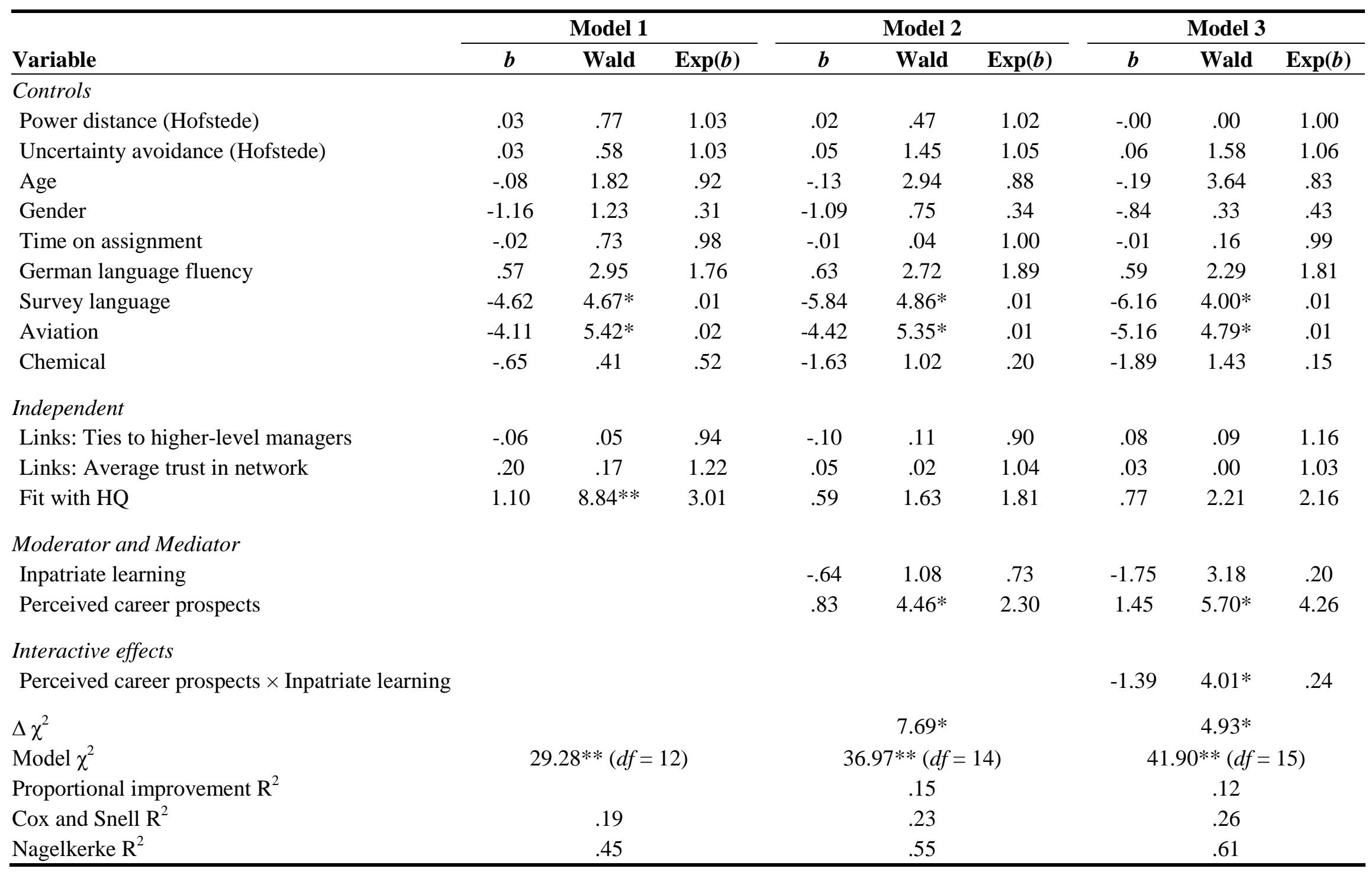

${ }^{\mathrm{a}}$ Values of $\operatorname{Exp}(b)$ above 1.0 indicate a positive effect, values of $\operatorname{Exp}(b)$ at 1.0 no effect, and values below 1.0 a negative effect; $\mathrm{n}=143 .{ }^{*} \mathrm{p}<.05$, ${ }^{* *} \mathrm{p}<.01$ 


\section{TABLE 5. Results of Logistic Regression Analysis of Inpatriate Four-Year Retention ${ }^{\text {a }}$}

\begin{tabular}{|c|c|c|c|c|c|c|c|c|c|}
\hline \multirow[b]{2}{*}{ Variable } & \multicolumn{3}{|c|}{ Model 1} & \multicolumn{3}{|c|}{ Model 2} & \multicolumn{3}{|c|}{ Model 3} \\
\hline & $\boldsymbol{b}$ & Wald & $\operatorname{Exp}(b)$ & $b$ & Wald & $\operatorname{Exp}(b)$ & b & Wald & $\operatorname{Exp}(b)$ \\
\hline \multicolumn{10}{|l|}{ Controls } \\
\hline Power distance (Hofstede) & .00 & .01 & 1.00 & -.00 & .00 & 1.00 & -.00 & .00 & 1.00 \\
\hline Uncertainty avoidance (Hofstede) & .02 & 1.58 & 1.02 & .03 & 2.69 & 1.03 & .03 & 2.44 & 1.03 \\
\hline Age & .04 & .78 & 1.04 & .04 & .56 & 1.04 & .04 & .65 & 1.04 \\
\hline Gender & -.94 & 2.31 & .39 & -1.05 & 2.26 & .35 & -1.07 & 2.32 & .34 \\
\hline Time on assignment & -.03 & $4.63^{*}$ & .97 & -.03 & 3.29 & .97 & -.03 & 3.36 & .97 \\
\hline German language fluency & .07 & .18 & 1.07 & .12 & .48 & 1.13 & .12 & .50 & 1.13 \\
\hline Survey language & -1.05 & 1.34 & .35 & -1.82 & 3.31 & .16 & -1.79 & 3.14 & .17 \\
\hline Aviation & -.91 & .48 & .40 & -1.05 & .68 & .35 & -1.06 & .69 & .35 \\
\hline Chemical & -1.16 & 3.46 & .31 & -1.67 & $5.21 *$ & .19 & -1.70 & $5.25 *$ & .18 \\
\hline \multicolumn{10}{|l|}{ Independent } \\
\hline Links: Ties to higher-level managers & .19 & 1.09 & 1.21 & .17 & .59 & 1.18 & .19 & .76 & 1.21 \\
\hline Links: Average trust in network & .18 & .31 & 1.20 & .18 & .30 & 1.22 & .15 & .27 & 1.16 \\
\hline Fit with HQ & .66 & $4.16^{*}$ & 2.05 & .17 & .36 & 1.19 & .19 & .44 & 1.21 \\
\hline \multicolumn{10}{|l|}{ Moderator and Mediator } \\
\hline Inpatriate learning & & & & -.42 & 2.38 & .71 & -.58 & 3.39 & .49 \\
\hline Perceived career prospects & & & & .57 & $5.27 *$ & 1.77 & .64 & $5.78 *$ & 1.89 \\
\hline \multicolumn{10}{|l|}{ Interactive effects } \\
\hline Perceived career prospects $\times$ Inpatriate learning & & & & & & & -.26 & .83 & .77 \\
\hline$\Delta \chi^{2}$ & & & & & $9.05 *$ & & & .82 & \\
\hline Model $\chi^{2}$ & \multicolumn{3}{|c|}{$22.34 *(d f=12)$} & \multicolumn{3}{|c|}{$31.39 * *(d f=14)$} & \multicolumn{3}{|c|}{$34.59 * *(d f=15)$} \\
\hline Proportional improvement $\mathrm{R}^{2}$ & & & & \multicolumn{3}{|c|}{.08} & \multicolumn{3}{|c|}{.01} \\
\hline Cox and Snell $\mathrm{R}^{2}$ & \multicolumn{3}{|c|}{.14} & \multicolumn{3}{|c|}{.19} & \multicolumn{3}{|c|}{.20} \\
\hline Nagelkerke $\mathrm{R}^{2}$ & \multicolumn{3}{|c|}{.24} & \multicolumn{3}{|c|}{.33} & \multicolumn{3}{|c|}{.34} \\
\hline
\end{tabular}

${ }^{\mathrm{a}}$ Values of $\operatorname{Exp}(b)$ above 1.0 indicate a positive effect, values of $\operatorname{Exp}(b)$ at 1.0 no effect, and values below 1.0 a negative effect; $\mathrm{n}=143 .{ }^{*} \mathrm{p}<.05,{ }^{* *} \mathrm{p}<.01$ 
FIGURE 1. Theoretical Model and Hypotheses

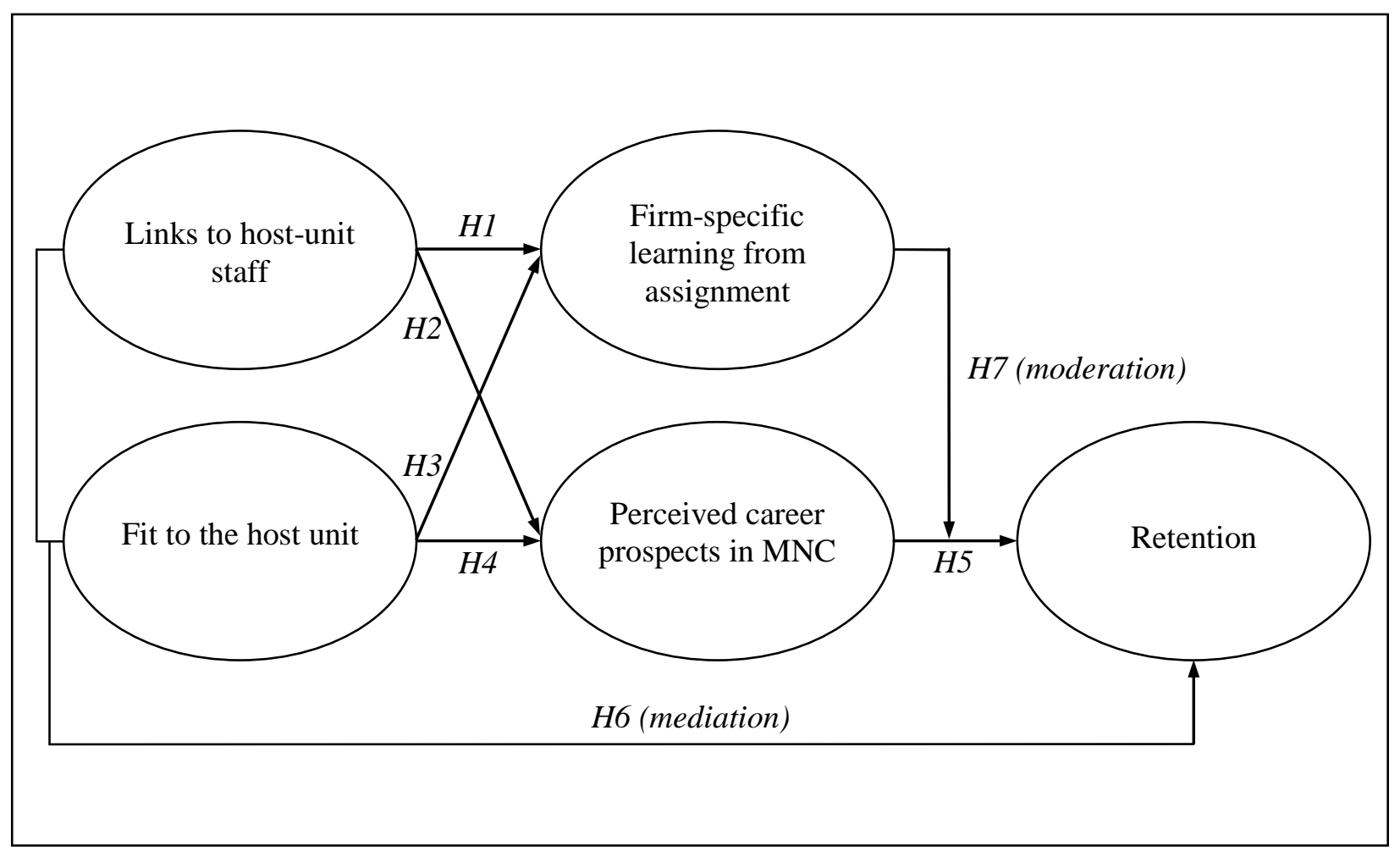


FIGURE 2. The Relationship between Perceived Career Prospects and Inpatriate Two-Year

Retention at High and Low Levels of Inpatriate Learning

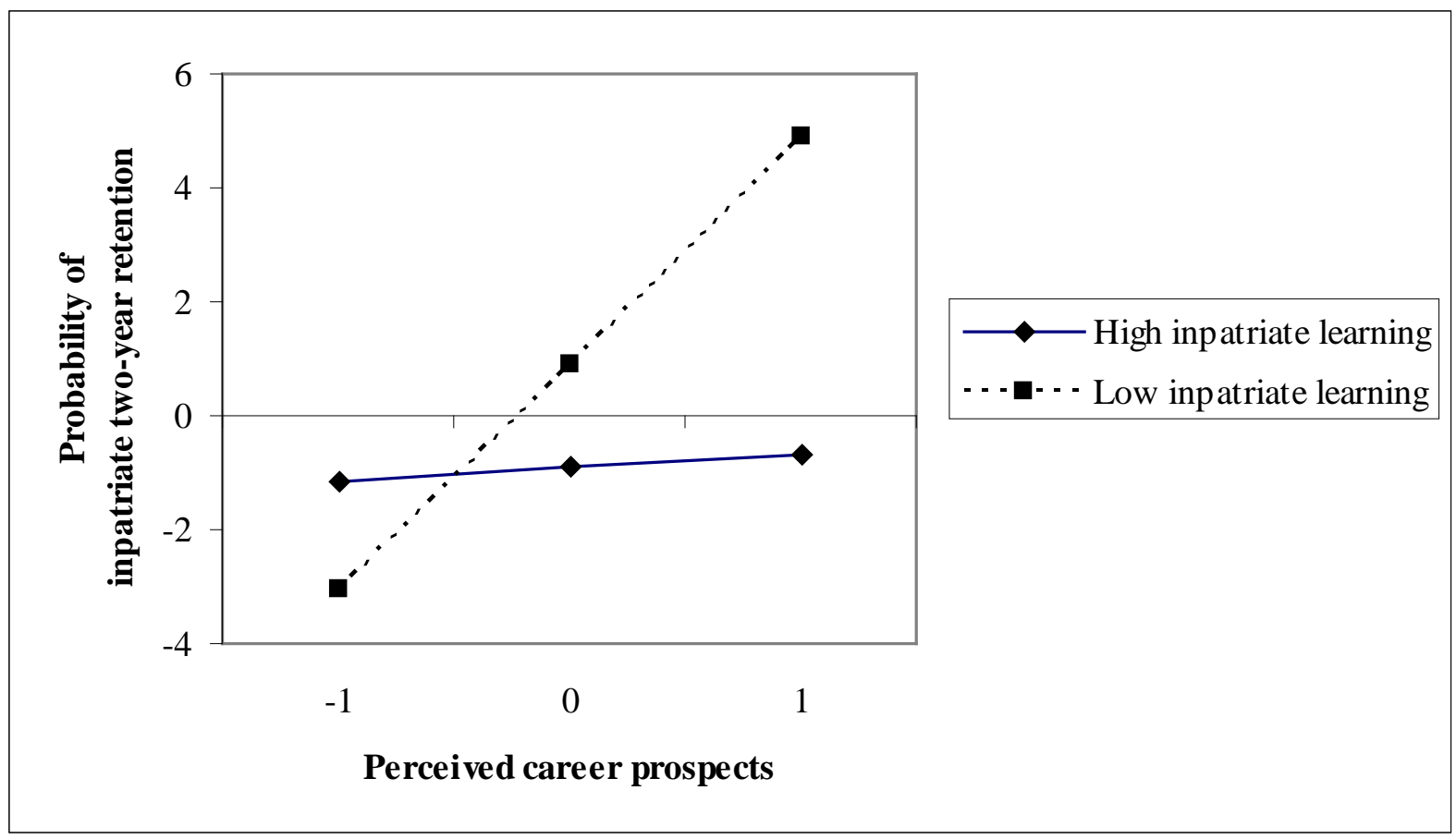




\section{APPENDIX. Scales of Perceptual Measures}

\section{Fit with the HQ}

$(1$ = strongly disagree to 7 = strongly agree $)$

(1) I share the same ambitions and vision with HQ management.

(2) I am enthusiastic about pursuing the collective goals and mission of the whole organization.

(3) I see no difference between my own values and the HQ's corporate values.

\section{Perceived Career Prospects}

$(1$ = strongly disagree to 7 = strongly agree $)$

(1) This company will provide me with future positions that build on my acquired knowledge, skills and contacts.

(2) The knowledge, skills and contacts that I have acquired/ will acquire during my assignment increase my chances of future employment in this company.

(3) This company will provide me with future positions that fit with my career goals.

(4) There are enough opportunities to pursue my career goals within this company.

(5) I am confident that I will achieve my career goals within this company.

\section{Inpatriate Learning}

(1 = strongly disagree to 7 = strongly agree $)$

During my assignment to the HQ I have:

(1) Acquired valuable knowledge that is instrumental for my professional development in the company.

(2) Acquired valuable knowledge that is instrumental for my personal development in the company.

(3) Learned the corporate culture.

(4) Learned how things are done at the HQ. 